\title{
Validation of a battery of inhibitory control tasks reveals a multifaceted structure in non-human primates
}

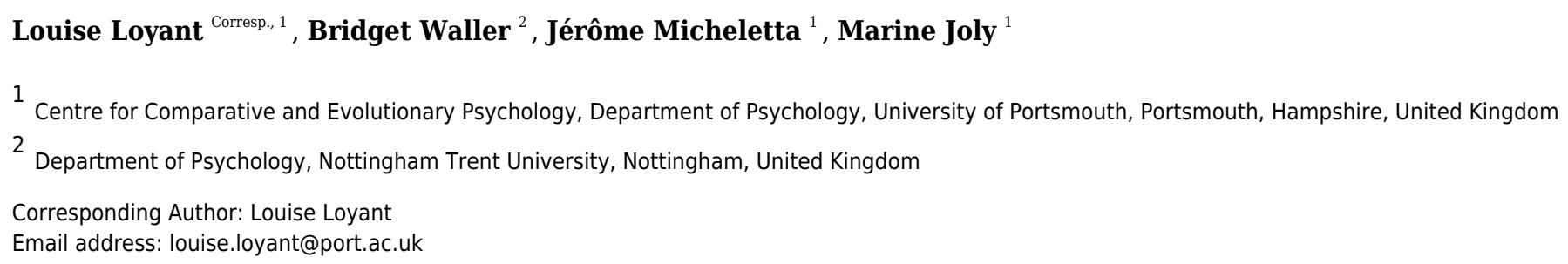

Inhibitory control, the ability to override an inappropriate prepotent response, is crucial in many aspects of everyday life. However, the various paradigms designed to measure inhibitory control often suffer from a lack of systematic validation and have yielded mixed results. Thus the nature of this ability remains unclear, is it a general construct or a family of distinct sub-components? Therefore, the aim of this study was first to demonstrate the content validity and the temporal repeatability of a battery of inhibitory control tasks. Then we wanted to assess the contextual consistency of performances between these tasks to better understand the structure of inhibitory control. We tested 21 rhesus macaques (Macaca mulatta, 12 males, 9 females) in a battery of touchscreen tasks assessing three main components of inhibitory control: inhibition of a distraction (using a Distraction task), inhibition of an impulsive action (using a Go/no-go task) and inhibition of a cognitive set (using a Reversal learning task). All tasks were reliable and effective at measuring the inhibition of a prepotent response. However, while there was consistency of performance between the inhibition of a distraction and the inhibition of an action, representing a response-driven basic form of inhibition, this was not found for the inhibition of a cognitive set. We argue that the inhibition of a cognitive set is a more cognitively demanding form of inhibition. This study gives a new insight in the multifaceted structure of inhibitory control and highlights the importance of a systematic validation of cognitive tasks in animal cognition. 


\section{Validation of a Battery of Inhibitory Control Tasks Reveals a Multifaceted}

\section{Structure in Non-Human Primates}

3 Louise Loyant ${ }^{1}$, Bridget Waller ${ }^{2}$, Jérôme Micheletta ${ }^{1}$ and Marine Joly ${ }^{1}$

$4 \quad{ }^{1}$ Centre for Comparative and Evolutionary Psychology, Department of Psychology, University

5 of Portsmouth, Portsmouth, United Kingdom

$6 \quad{ }^{2}$ Department of Psychology, Nottingham Trent University, Nottingham, United Kingdom

7

8 Corresponding Author:

9 Louise Loyant ${ }^{1}$
Department of Psychology, King Henry I Street, King Henry Building, Portsmouth PO1 2DY, United Kingdom

Email address: louise.loyant@port.ac.uk 


\section{Abstract}

20

21

22

Inhibitory control, the ability to override an inappropriate prepotent response, is crucial in many aspects of everyday life. However, the various paradigms designed to measure inhibitory control often suffer from a lack of systematic validation and have yielded mixed results. Thus the nature of this ability remains unclear, is it a general construct or a family of distinct sub-components? Therefore, the aim of this study was first to demonstrate the content validity and the temporal repeatability of a battery of inhibitory control tasks. Then we wanted to assess the contextual consistency of performances between these tasks to better understand the structure of inhibitory control. We tested 21 rhesus macaques (Macaca mulatta, 12 males, 9 females) in a battery of touchscreen tasks assessing three main components of inhibitory control: inhibition of a distraction (using a Distraction task), inhibition of an impulsive action (using a Go/no-go task) and inhibition of a cognitive set (using a Reversal learning task). All tasks were reliable and effective at measuring the inhibition of a prepotent response. However, while there was consistency of performance between the inhibition of a distraction and the inhibition of an action, representing a response-driven basic form of inhibition, this was not found for the inhibition of a cognitive set. We argue that the inhibition of a cognitive set is a more cognitively demanding form of inhibition. This study gives a new insight in the multifaceted structure of inhibitory control and highlights the importance of a systematic validation of cognitive tasks in animal cognition. 


\section{Introduction}

43

44

45

Living in a complex social environment requires animals to manage their impulsive behaviours to maintain group cohesion and survival. For example, in the presence of a higherranking conspecific, an individual needs to inhibit aggressive behaviours when competing over food (Amici, Aureli \& Call, 2008; Byrne \& Bates, 2007) or over a mating partner (Estep et al., 1988; Lyndsay et al., 1976). These inhibitory processes constitute core components of executive functions; a family of top-down cognitive control processes which support goal directed behaviours (Aron, 2007; Banich, 2009; Diamond, 2013; Duque \& Stevens, 2017; Miyake et al., 2000; Nigg, 2017). Here we define inhibitory control as the ability to deliberately control a reflexive, automatic, or pre-learned response and therefore achieve a more complex goal (Dempster \& Corkill, 1999; Dillon \& Pizzagalli, 2007; Friedman \& Miyake, 2017; Miller et al., 2019; Miyake et al., 2000). A strong internal predisposition or an external distractor, tempting but counterproductive, irrelevant to the individual's goal, must be overridden in order to do what is more appropriate or needed (Diamond, 2013; Dillon \& Pizzagalli, 2007; Nigg, 2017). To cover the main domains of inhibitory control, we focus particularly on three of the most commonly described inhibitory processes in the literature: distraction inhibition (e.g., control of an emotional response to an internal or external distractor, in order to focus on a goal), action inhibition (e.g., inhibition of a prepotent, unwanted, reflexive motoric action) and cognitive set inhibition (e.g., inhibition of a pre-learned cognitive set to flexibly adjust behaviours; see Aron, 2007; Diamond, 2013; Dillon \& Pizzagalli, 2007; Nigg, 2017).

An important research question that has been a source of controversy in both neuropsychological and cognitive studies is to what extent these inhibitory processes can be considered unitary in the 
64 sense that they are reflections of the same underlying mechanism or ability (Dempster \& Corkill,

65 1999; MacLeod, 2007; Miyake et al., 2000; Nigg, 2017). For instance, to support this unitary

66 hypothesis, Duckworth and Kern (2011), in a large-scale meta-analysis (based on over 33,000

67 adult participants), demonstrated a moderate but significant convergence of several inhibition related measures such as the Go/no-go task (the subjects need to respond to Go stimuli while inhibiting response to an unrewarded No-go stimuli) or the Stroop task (the subjects need to inhibit an interference from a distractor while doing a task). Similarly, in the animal cognition field, MacLean et al. (2017) found that the cylinder task (a common inhibitory control task in which the animal needs to inhibit reaching directly for food through the transparent surface of a cylinder) and 2 detour tasks (the subject needs to circumvent an obstacle to get a reward) loaded onto the same factor in a large-scale battery of cognitive tasks in 552 dogs (Canis familiaris). Maclean et al. (2014) also found a strong correlation in performances between the A-not-B task (the subject must inhibit a previously rewarded behaviour to learn a new reward-contingency) and the cylinder task across 23 primate species.

In contrast, several authors have proposed that inhibition-related processes are instead a family of functions rather than a single unitary construct (Friedman \& Miyake, 2004, 2017; Nigg, 2000, 2007). In humans, Friedman and Miyake (2004), using common inhibitory control tasks, found that two inhibitory factors: "prepotent response inhibition" and "resistance to distractor interference" were closely related, but both were unrelated to "resistance to proactive interference", a form of cognitive set inhibition. In the animal cognition literature, several studies tested dogs ( $C$. familiaris) in common inhibitory control tasks, including the Cylinder and the Anot-B. The authors found that the dogs' performances in these tasks were not correlated (Bray, 
87 similar result was also found in a study comparing wolves (Canis lupus) and dogs' performances

88 in a cylinder task and in a detour paradigm (Marshall-Pescini, Virányi and Range, 2015). From

89 these results, the authors concluded that inhibitory control would be context specific and of a

90 diverse structure (Bray, MacLean \& Hare 2014; Brucks et al., 2017; Fagnani et al., 2016;

91 Vernouillet et al., 2018).

92 However these mixed results and lack of correlation are difficult to interpret as evidence for

93 separable inhibition-related processes for several reasons (Friedman \& Miyake, 2004; Miyake et

94 al., 2000). The first reason is that researchers often use these tasks and assume that they measure

95 inhibitory control but without providing any justification of the choice of the task (Friedman \&

96 Miyake, 2004). Thus the content validity (defined as the degree to which a measurement is

97 representative of the targeted construct, Haynes, Richard \& Kubany, 1995) is rarely evaluated

98 (Friedman \& Miyake, 2004). According to Völter et al. (2018), to assess the content validity of a

99 task, researchers should agree on features defining the ability of interest and look at

100 characteristic responses' patterns. For instance, in inhibitory control tasks authors should

101 demonstrate that a prepotent response (dominant and automatic response to a stimulus) have

102 been triggered by the test conditions (Völter et al., 2018).

103 The second complication arises from the fact that common inhibitory control tasks tend to suffer 104 poor repeatability, i.e. multiple exposures to the same task often lead to inconsistent individual's 105 performance over time (Miyake et al., 2004, Völter et al., 2018). Yet this test-retest reliability is 106 necessary before considering the validity of a task (Biro and Stamps, 2015; Griffin, Guillette \& 107 Healy, 2015; Völter et al., 2018). In the animal cognition literature, the repeatability of inhibitory 108 control measurements is rarely assessed, and the results are mixed. For instance, great tits (Parus 109 major) demonstrated a significant repeatability of performances in successive reversal learning 
110 tasks (Cauchoix et al., 2017). Similarly, Australian magpies (Cracticus tibicen) tested as

111 juveniles in the cylinder task and reversal learning task repeated their performance as adults

112 (Ashton et al., 2018). However, the performance of robins (Petroica longipe) in the cylinder task

113 did not seem repeatable over a year (Shaw, 2017). This lack of valid and reliable cognitive

114 measurements, often referred as the "replicability crisis", is unfortunately a common issue in

115 psychology experiments (for review see Lindsay, 2015).

116 A third difficulty is the task impurity problem, i.e. no tasks are pure measurement of a single

117 cognitive process. Inhibitory control tasks often involve other cognitive (e.g. memory) or non-

118 cognitive processes (e.g. personality) that are not directly relevant to the targeted function

119 (Friedman \& Miyake, 2004; Gärtner \& Strobel, 2019; Miyake et al., 2000; Völter et al., 2018).

120 For instance, the cylinder tasks, one of the benchmark tests in large inter-species comparisons

121 (MacLean et al., 2014, 2017), is the subject of vivid debates (for review see Kabadayi,

122 Bobrowicz \& Osvath, 2018; Shaw \& Schmelz, 2017). Factors such as prior experience (Duque \&

123 Stevens, 2017; Kabadayi, Bobrowicz \& Osvath, 2018; van Horik et al., 2019; Vernouillet et al.,

124 2018), can dramatically influence a subject's performance on this detour task. Various authors

125 advocate to circumvent this task impurity problem by using a battery of tasks putatively

126 measuring the same ability (but differing in other task demands) to reveal a common underlying

127 cognitive construct (Cauchoix et al., 2018; Friedman and Miyake 2017; Many Primates et al.,

128 2019; Shaw \& Schmelz, 2017; Völter et al., 2018). If inhibitory control was a common ability,

129 multiple tasks putatively measuring the same inhibitory process, should demonstrate cross-

130 contextual consistency in individuals' inhibitory performance (Shaw \& Schmelz, 2017; Völter et

131 al., 2018). 
132 Therefore, the aim of this study was to validate a battery of inhibitory control tasks in non-

133 human primates: (1) by assessing the content validity of three tasks covering the main domains

134 of this inhibitory ability, (2) by demonstrating the necessary temporal repeatability of these tasks.

135 Finally, we wanted to investigate the structure of inhibitory control by looking at the cross-

136 contextual consistency between tasks. The goal here was to assess whether the main components

137 of inhibitory control fall under the same common inhibitory ability or whether they are part of a

138 family of distinct sub-components.

139 Rhesus macaques (Macaca mulatta), phylogenetically close to human species, represent an

140 interesting model for our battery of inhibitory control tasks. This species, exhibits complex social

141 organisation (Thierry, 2000), possesses enhanced general intelligence (Reader \& Laland, 2002)

142 and can perform computerized testing (e.g., Gazes et al., 2013; Washburn 1994; Washburn,

143 Harper \& Rumbaugh, 1994). The Macaca genus has been tested in several inhibitory control

144 tasks, for instance researchers have demonstrated the Stroop effect (interference effect of an

145 incongruent stimulus, Lauwereyns et al, 2000) and the emotional Stroop effect in Japanese

146 macaques (Macaca fuscata; Hopper et al., 2021). Barbary Macaques (Macaca sylvanus) have

147 been tested in a modified version of the cylinder task and in cognitive flexibility tasks (Rathke \&

148 Fischer, 2020). Rhesus macaques have also been tested in reversal learning tasks (Rayburn-

149 Reeves \& Beran, 2017) and in a stop task associated with emotional pictures (Vardanjani et al.,

150 2021). We developed a battery of touchscreen tasks of inhibitory control from well-established

151 tasks used in human and animal research, and which have been tested for validity and reliability

152 (Rana \& Rao, 2013; Thomas, Rao \& Devi, 2016; Wöstmann et al., 2013). The touchscreen

153 technology is an extremely flexible tool which allows accurate record of subject's answer while

154 controlling for important confounding factors (Kangas \& Bergman, 2017). We focused on the 
155 major components of inhibitory control. To investigate the inhibition of a distraction, we

156 conducted a Distraction task. In this task, a subject must inhibit a dominant and prepotent

157 emotional response to a distractor (Allritz, Call \& Borkenau, 2016; Bethell et al., 2016; Isaac et

158 al., 2012; Stroop, 1935). To investigate the inhibition of an action, we conducted a Go/No-go

159 task. Here a subject learns to develop a prepotent motor response to frequently appearing target

160 and must withhold it to less frequently appearing non target (Aron, 2007; Diamond, 2013; Dillon

161 \& Pizzagalli, 2007; Duckworth \& Kern, 2011). Lastly, to assess inhibition of a cognitive set, we

162 conducted a Reversal learning task. In this task, a subject must inhibit a pre-learned rule to adopt

163 a new set of rules (Bray, MacLean \& Hare, 2014; Jelbert, Taylor \& Gray, 2016).

164 We first expected to demonstrate the content validity of our three inhibitory control tasks, i.e. a

165 prepotent response (dominant and automatic response to a stimulus) was generated by the test

166 conditions. We further expected to demonstrate temporal repeatability of the tasks by showing

167 that the rank of the individual's performances within the group of subjects and within the same

168 task, would be repeatable over two time points (2 weeks apart). On one hand, we did not want

169 this interval to be too long to avoid dramatic changes in the internal and external states of the

170 subjects (Bell, Hankison \& Laskowski, 2009; Shaw \& Schmelz, 2017). On the other hand, we

171 did not want this interval to be so short that there would be an influence of carry over effects

172 (Bell, Hankison \& Laskowski, 2009). Finally, we expected that these 3 tasks would not

173 demonstrate cross-contextual repeatability of the individuals' performances thus supporting the

174 theory of the multifaceted structure of inhibitory control.

\section{Materials \& Methods}

176 Data were collected as previously described in Loyant et al., 2021. 


\section{Subjects}

178 All the adult rhesus macaques (M. mulatta) taking part in this study were from the breeding

179 colony of the Medical Research Council's Center for Macaques (MRC-CFM) in Porton Down,

180 United Kingdom. Each group had access to an indoor free-roaming room $(3.35 \mathrm{~m} \times 8.04 \mathrm{~m} \times$

$1812.8 \mathrm{~m})$ and an adjacent caged area $(1.5 \mathrm{~m} \times 6.12 \mathrm{~m} \times 2.8 \mathrm{~m})$, with a minimum total space of $3.5 \mathrm{~m} 3$

182 /breeding animal in the largest groups. All rooms were temperature controlled $\left(20{ }^{\circ} \mathrm{C} \pm 5\right)$ with

183 humidity at 55\% +/-10. Each free-roaming area had a large bay window at one end facing

184 outdoors and allowing a natural day-night cycle. At the other end of each room was an internal

185 window fitted with movable mirrors which the monkey could control using a handle, allowing

186 them to view the activities outside their area. Rooms were enriched with climbing structures

187 (platforms, poles, fire hose and ladders) and enrichment devices (food puzzles, boxes, plastic

188 barrels and balls, and small plastic blocks attached to structures or walls). Subjects received a

189 supply of fruit and vegetables, dried forage mix (cereal, peas, beans, lentils etc.), bread and

190 boiled eggs, in the morning and afternoon, with enough food to last for a $24 \mathrm{~h}$ period. All

191 subjects had access to water and food prior to and during the experiment. Eighteen of the

192 subjects already participated in a behavioural study involving looking at pictures (Bethell et al.,

193 2019, unpublished paper) and all of them were familiar with basic training and clicker

194 procedures. However, none of them had experience with touchscreen experiments. Thirty

195 subjects (14 males, 16 females; aged from 3 to 17 years old, mean age in years $\mathrm{M} \pm \mathrm{SD}=8.10 \pm$

$1964.05, \mathrm{~N}=30$ ) started the touch screen training phases (see Supplemental materials Training

197 phases) but only 21 (12 males and 9 females, aged from 3 to 17 years old, mean age in years $\mathrm{M} \pm$

$198 \mathrm{SD}=8.9 \pm 4.41)$ successfully completed the training and were able to take took part in the

199 experiment. The subjects were housed in 14 different social groups with an average of 12

200 individuals per group. Hierarchy, calculated in each group using David's scores (David, 1987), 
201 was provided by the head of research of the facility (see Supplemental materials, Rank

202 calculations). Agonistic behaviours including threats, displacements, chases, and physical

203 conflict were recorded to assess the hierarchy. The caretakers regularly monitored the groups,

204 and David's scores were updated accordingly. Using video recordings of training and test

205 sessions, a blind observer coded agonistic interactions between the tested individual and other

206 conspecifics to verify the given ranks for each group (see Supplemental material). If a male

207 never lost, he was considered high ranking. If the female never lost against other females, she

208 was considered high-ranking, otherwise she was considered low-ranking.

\section{Ethics}

210 This study was approved by the Animal Welfare and Ethical Review Body of the University of

211 Portsmouth, AWERB no. 4015B and by the MRC-CFM's Animal Welfare and Ethical Review

212 Body, ARWEB no. CFM2019E002 and was part of the Macaque Cognition Project. All research

213 was carried out in accordance with ethical guidelines for work with non-human primates (NC3Rs

214 2006).

215 Apparatus

216 To minimise stress, all tests were conducted in the enclosure, with no isolation from the social

217 group; meeting recent and important ethical considerations on animal welfare and cognition

218 (Cronin et al., 2017; Jacobson et al., 2018). The macaques had free and voluntary access to the

219 apparatus and were never restrained; at any point subjects could leave the experiment and return

220 voluntarily. For the experimental task, the set up was customized to be transported from one cage

221 to another. Outside the cage, a laptop was connected via USB and HDMI cables to a capacitive

222 touchscreen (ELO 1590L, frequency of $60 \mathrm{~Hz}, 19$ ” in diagonal, resolution $1280 \times 1024$ pixels).

223 The program Elo touch solution 6.9.20 was used for calibration. The laptop screen duplicated the 
224 touchscreen display to be able to follow the experiment's progress. The touchscreen was attached

225 to the cage bars and the position was adjusted to each individual. All experimental procedures

226 including stimulus presentation and response collection were carried out using MATLAB

227 (version R 2018b, using Psychtoolbox-3.0.15 functions), under Windows 10. The MATLAB

228 scripts were specifically conceived for the needs of this study; an individual progression file

229 allowed the experimenter to abort and come back to the same point of a running session (see

230 online supplemental material for MATLAB CODE). If a trial was aborted the response latency

231 was not recorded. The computer gave auditory feedback in response to the subject's

232 performance. All sessions were videotaped with one digital video camera (Sony HDR-

233 CX330EB). The rewards (dry raisins) for each correct answer were given by hand.

234 General Procedure

235 When the program for a specific task was launched, the experimenter entered the name of the

236 individual. When more than one individual per cage were tested or when other individuals from

237 the group were interacting with the touch screen, a research assistant was distracting the other

238 macaques at the opposite side of the room. Every session was initiated by the subject touching a

239 red cross located in the centre of the screen, starting the time recording. The session was aborted

240 when another individual displaced the tested individual or interacted with the touchscreen. If the

241 subject left the testing area or was not focusing attention on the screen the session was aborted. If

242 the target was not touched within the specified time limit (see task descriptions below for

243 specific time limit), the built-in timer of the program was paused, and a red cross appeared in the

244 centre of the screen until the session was resumed by touching it. The response latencies above

245 the time limits were not used in the analysis. If the subject stayed inactive for more than 5 min 
246 the experiment was stopped and continued the next testing day, if the subject did not participate

247 for three testing days in a row the subject was excluded from the task.

\section{Inhibitory control tasks}

249 For the task battery we chose three tasks covering the main domains of inhibitory control:

250 inhibition of distraction, inhibition of action and inhibition of a cognitive set (see Fig. 1). The

251 tasks were conducted in the same order as they were built upon the previous task (see Fig. 1 for a

252 visual presentation of the tasks and timeline): first a Distraction task (a target touching task with

253 pictorial stimuli as distractors). This task was repeated (to assess temporal repeatability), for each

254 subject, 2 weeks apart. Once this task was completed for the second time, the subjects were

255 tested (the next testing day) on the Go/No-go task (a novel unrewarded stimulus was introduced).

256 Once, the subjects were tested a second time on the Go/No-go task, they were tested on the

257 reversal learning task (built upon the previously rewarded and unrewarded stimuli). Finally they

258 finished the experiment by being tested a second time on the Reversal learning task 2 weeks

259 after. As in previous batteries of tasks in animals (Beran \& Hopkins, 2018, Herrmann et al.,

260 2007, 2010, Lacreuse, 2014, Maclean et al. 2017; Wobber et al., 2014), the order of tasks was the

261 same for all subjects. Although this design cannot eliminate the possibility of order effects (i.e.

262 the participation on a given task affects performance on subsequent measures), it ensures

263 consistency across subjects, permitting direct comparisons of performances across time and

264 tasks. Besides, we wanted our subject to have the same experience with inhibitory control testing

265 as this ability can be learned (Diamond, 2013) and is directly influenced by previous inhibitory

266 control testing (Radel, Gruet \& Barzykowski, 2019). 


\section{Inhibition of Distraction: Distraction task}

268 The Distraction task we used is a variant of the Emotional Stroop task in which human

269 participants name the colours of words that differ in emotional valence, with a longer response

270 latency to negative words (Bar-Haim et al., 2007; Williams, Mathews \& MacLeod, 1996). We

271 used a simplified version of the Emotional Stroop task (Allritz, Call \& Borkenau, 2016, in

272 chimpanzees, Pan troglodytes) in which a prepotent response to an emotional stimulus interferes

273 with the goal of the task.

\section{Design}

275 Every session was initiated by the subject touching a red cross in the centre of the screen. Then

the timer started, and the subject had to touch a target (a red rectangle of $10 \times 13 \mathrm{~cm}$ ) randomly

displayed at the far left or right of the screen. When the subject successfully touched the target, a

high-pitched chime was played, the timer was stopped, and the reward was given. After an inter-

trial of $2000 \mathrm{~ms}$ with only a white background displayed, the next trial was presented. Such a

trial without a distractor was considered as a "Control" trial. Two "Control" trials were followed

by a block of four trials with pictures from the same categories (either four pictures of objects,

neutral or threatening conspecific faces, see Fig. 1 and online supplemental materials for

MATLAB codes and stimuli). Each block of pictures of the same category was seen 2 times per session. From the literature, it appeared that the Stroop effect was more pronounced with this

block presentation of pictures (in humans Bar-Haim et al., 2007; McKenna \& Sharma, 2004 and in chimpanzees, P. troglodytes, Allritz, Call \& Borkenau, 2016). The distractors were displayed at the centre of the screen at the same time as the regular target. The distractors were pictures of 16 x $18.5 \mathrm{~cm}$ with matching contrast and luminosity (function 'Match colour' in Adobe 
290 a wooden log. The conspecific pictures were chosen to be as realistic as possible, depicting a

291 frontal view of the face and the torso of four unknown adult rhesus macaques. The "Neutral"

292 conspecific included four pictures of individuals with a neutral facial expression. The

293 "Threatening" conspecific included four pictures showing a "open mouth threat" facial

294 expression, frequently displayed by rhesus macaques (Bethell et al., 2016). Threatening stimuli

295 (as well as positive stimuli see Hopper et al., 2021) have been shown to have an important

296 distracting effect in macaques (Bethell et al., 2016; Landman et al., 2014). The subjects were not

297 rewarded to touch the distractors and the screen remained the same until the target on the side

298 was touched. During a pilot study $(\mathrm{N}=4$ subjects, these data were not included in our analysis),

299 we observed that the subjects were, for a long duration, intensely reacting to the pictures of their

300 conspecifics' faces (lip-smacking, stares and threats) so we set up a maximum response time of

$30135 \mathrm{~s}$ (at the condition that the subject kept looking at the screen). This time period allowed the

302 subject to display a behavioural response, overcome it, and continue the task. If the subject did

303 not touch the target within $35 \mathrm{sec}$, the response latency was not taken into account in the

304 analysis. Each block and trial were counterbalanced across subjects (see Fig. 1). Three sessions

305 of 36 trials were repeated at time point 1 and time point 2 (average days between the time points

$306 \mathrm{M} \pm \mathrm{SD}=12.91 \pm 2.84, \mathrm{~N}=21 ; 216$ trials total per individual). One male rhesus macaque was

307 not willing to participate in further testing after this task.

\section{Inhibition of action: Go/No-go task}

309 In the Go/No-go task the subjects need to respond to frequently presented Go stimuli while

310 withholding a prepotent response to infrequently presented No-go stimuli (Dillon and Pizzagalli

311 2007; Duckworth and Kern 2011; Müller et al., 2012). 


\section{Design}

313 The apparatus and the general procedure were identical to the Distraction task. A "Go" (red

314 rectangle of $16 \times 18 \mathrm{~cm}$ ) or a "No-go" stimulus (green circle of 16x16 cm) appeared randomly in

315 the centre of the screen. The "Go" stimulus was preceded by a high-pitched sound ( $0.6 \mathrm{sec}$

316 before the stimulus appeared) and the "NoGo" stimulus a low pitch sound to help the subjects to

317 anticipate the next trial. The "Go" stimuli appeared $75 \%$ of the 40 trials to elicit a prepotent

318 response toward the screen. If the screen was touched outside the stimulus no sound was

319 produced and the trial continued. The "Go" stimulus stayed on the screen until it was touched.

320 We set up a maximum response time (i.e. touching the "Go" stimuli) of $15 \mathrm{~s}$ after this the red

321 cross appeared on the screen and the response latency was not recorded. From a pilot study

322 conducted with a shorter response limit, we observed that the subjects frequently left the testing

323 session as they were not rewarded on each "Go" trial. The "No-go" stimulus disappeared if not

324 touched during $2000 \mathrm{~ms}$ and the subject received a reward. If the "No-go" stimulus was touched

325 during this lapse of time, a blank white background appeared for $3000 \mathrm{~ms}$ (as a time out), an

326 "incorrect" sound (with frequency 800, 1300, $2000 \mathrm{~Hz}$ ) was produced and the reward was not

327 given. At first, we fixed a success criterion for the subject's performances at $80 \%$ of correct trials

328 per session, but four macaques never reached this criterion. The performance was therefore

329 measured after 5 sessions of 40 trials per time point ( 200 trials in total) for each monkey. These

330 sessions were repeated at time point 2 (average days between the time points $\mathrm{M} \pm \mathrm{SD}=11.95 \pm$

331 2.10, $\mathrm{N}=20$, see Fig. 1).

\section{Inhibition of a cognitive set: Reversal learning task}

333 In the Reversal learning the subjects first learn a stimulus-reward contingency. Once a pre-

334 specified criteria is reached this first association is reversed. Subjects must then inhibit a 
335 prepotent response to previously correct stimuli and shift responses to a new stimulus-reward

336 contingency (as in Bond, Kamil \& Balda, 2007; Tapp et al., 2003). We expected that the subjects

337 would be able to learn a simple discriminant rule and successfully inhibit it.

338 Design

339 At the beginning of the task, two stimuli, a "Go" rewarded stimulus (a red square of $15.34 \mathrm{x}$

$34015.34 \mathrm{~cm}$ ) and a "No-go" unrewarded stimulus (a green circle of $15.34 \mathrm{~cm}$ of diameter), were

341 displayed at the same time on the screen at counterbalanced locations (left or right of the screen).

342 When the subject touched the "Go" stimulus, the usual "correct" sound was played, the subject

343 received a reward, and a new trial began. If the subject touched the incorrect stimulus the

344 "incorrect" sound was played, the subject did not receive a reward and the two stimuli stayed on

345 the screen until the correct stimulus was touched. If the background was touched nothing

346 happened. We set up a maximum response time (i.e. touching the "Go" stimuli) of $15 \mathrm{~s}$ after this

347 the red cross appeared on the screen and the response variables were not recorded. We set up this

348 response limit to keep the subjects engaged with the task. From a pilot study we observed that

349 this period of time allowed the subject to frequently receive a reward and to keep engaged with

350 the task. A session consisted of 40 trials. Once a criterion of success was achieved (75\% of

351 correct trials out of 20 trials, i.e. the subjects touched the correct stimulus from the first attempt),

352 the rule was reversed: the correct stimulus became the incorrect and the incorrect the correct.

353 One male macaque was excluded from the study as he did not reach the first criterion. The

354 reversed session was continued until the success criterion was reached again $(75 \%$ of success for

355 the whole session). Three sessions of the reversed paradigm were repeated at time point 2

356 (average days between the time points $\mathrm{M} \pm \mathrm{SD}=12.74 \pm 5.06, \mathrm{~N}=20$ ). One male subject could

357 not participate in the second time point test as it was permanently removed from the facility. 


\section{Content validity}

\section{Analysis}

360 To validate our battery of inhibitory control tasks we first wanted to assess the content validity of

361 these tasks, for this we wanted to demonstrate that a prepotent response had indeed been

362 triggered (Völter et al., 2018). In the Distraction task, we expected a prepotent response to be

363 triggered by the pictorial distractors, which would increase the response latency of the subjects in

364 a trial with pictures. We expected a greater response latency when a picture was presented,

365 particularly in the trials with the negative stimuli, compared to control trials with no picture (as

366 in Allritz, Call \& Borkenau, 2016; Bethell et al., 2016, in non-human primates). We also

367 expected to demonstrate that the subjects would still be able to perform the task by overriding

368 their prepotent response to the distractors, keeping a general high rate of success in the task (i.e.

369 successfully touching the target within the time limit).

370 To assess the content validity of the Go/No-go task, we wanted to demonstrate that a prepotent

371 response was triggered (an incorrect impulsive action toward the No-go stimulus). Therefore, we

372 investigated the difference in response accuracy in the Go and No-go trials. We expected it to be

373 lower on a No-go trial compared to a Go trial. We also expected the subjects to try to override

374 their impulsive response in the No-go trial, with a greater response latency compared to a Go 375 trial.

376 In the Reversal learning task, we expected an interference from the previously learnt rule while

377 learning the new rule. We expected a lower probability of success in learning the reversed rule

378 (Rule 2) compared to the first acquisition rule (Rule 1). However, we still expected that the

379 subjects override this interference from the first rule with an overall high accuracy for the second 
380

381

382

383

384

386

387

388

389

390

391

392

393

394

395

396

397

398

399

400

401

402

rule. We used a Wilcoxon one sample test to check that the previous task did not reinforce the subjects' responses toward the red stimuli (even though the location and size were different).

All analyses were conducted in the R environment for statistical computing v.3.6.0 (R Core Team 2019). We used linear mixed models and general linear model using the functions 'Ime' from the R package 'nlme' v3.1-144 to analyse continuous variable (Harrison et al., 2018) and the function 'glmer' from the R package 'lme4' v1.1-21 to analyse the binary variable (Bates et al., 2015). The dependent variables were the response latency to touch the target on a trial in the Distraction task and in the Go/No-go task (continuous). As the response latency data presented a skewed distribution, they were log transformed to meet assumptions of normality (Cauchoix et al., 2018; Fazio, 1990; Harald et al., 2010). We excluded latencies below $200 \mathrm{~ms}$ (time needed for stimulus perception and motor responses to occur, Harald et al., 2010; Whelan, 2008) and above the time limit. We also recorded the successful completion of a trial in the Go/No-go task and in the Reversal learning task (binary). For all tasks, the random factor included the individual's identity. We controlled for known influencing factors of inhibitory control by including the following explanatory variables into the models: the sex of the subject (Paul, Harding \& Mendl, 2005; Sass et al., 2010), the age (in year, Tapp et al., 2003; Bray, MacLean \& Hare, 2014), the experience with pictures (for the Distraction task) and the rank of the subject (Johnson-Ulrich \& Holekamp, 2020). To increase the power of the analysis we merged middle ranked individuals and low ranked individuals to have 2 categories of ranks : either low or high. We had a total of 16 individuals from the higher rank and five from the lower rank. We also controlled for the following task influencing factors: trial, session, time point and type of stimulus (type of picture, no picture vs any type of picture for the Distraction task, type of stimulus: Go vs No-go in the Go/No-go task and type of rule: acquisition or reversed rule in the 
403 Reversal learning task). The full model contained all probable explanatory variables

404 (demographic and task determinants). Terms were sequentially dropped from the full model,

405 until the best fitted model contained only those terms that could not be removed without

406 significantly reducing explanatory power (Bates et al., 2015; Harrison et al., 2018). We used the

407 function 'anova' from the R package 'car' v3.0-6 to compare each model by likelihood ratio test

408 (given as : $\chi^{2}$ (Degree of freedom, $\mathrm{N}=$ sample size)). Our significant threshold was $\mathrm{p}<0.05$.

409 Visual inspection of residual plots did not reveal any obvious deviations from normality. We

410 presented the mean \pm the standard error for each effect of the explanatory variable on the

411 outcome. Data are available on an online repository (see online supplemental materials, DATA

412 SET).

413 Results

414 Content validity, Distraction task

415 There were no significant differences between each type of picture ('Threat', 'Neutral' or

416 'Object') in the overall performances but there was a significant difference in the mean response

417 latency between the trials without pictures (control trial, $\mathrm{M} \pm \mathrm{SE}=3961.78 \pm 104.52 \mathrm{~ms}, \mathrm{~N}=21$ )

418 and with any type of picture (test trials, $\mathrm{M} \pm \mathrm{SE}=4496.52 \pm 111.17 \mathrm{~ms}, \mathrm{~N}=21$, likelihood-ratio

419 test, $\chi^{2}(1, \mathrm{~N}=21)=9.98, \mathrm{p}=0.002$; see Fig. 2 and Supplemental materials Table S1 for more

420 details and for the presentation of the effects of the other explanatory variables). This indicates

421 that the response latency was higher when a picture was present, showing that the subjects were

422 distracted. Nonetheless, when a picture was present the percentage of success on the task (to

423 touch the target within the time limit) was still high (96\%) showing that this prepotent response

424 was overridden by the subjects. Thus, the interference from a distractor was inhibited in order to

425 successfully complete the task, these results indicate the content validity of this first task. 


\section{Content validity, Go/No-go task}

427 There was a significant difference in the mean successful completion of the task between the

428 trials with the Go signal or the No-go signal (likelihood-ratio test, $\chi^{2}(1, \mathrm{~N}=20)=3335.6, \mathrm{p}<$

4290.001 , see Fig. 2 and Supplemental materials Table S2). With only a mean of $47.3 \pm 1.09 \%(\mathrm{~N}=$

430 20) of correct answers when a No-go signal was presented (i.e. not touching the No-go stimulus),

431 compared to a mean of success (i.e. touch the Go stimulus within the time limit) of $99.8 \pm 0.04$

$432 \%(\mathrm{~N}=20$, see Fig. 2) when it was a Go stimulus presented. This result is showing that a

433 prepotent response, touching the target impulsively was triggered as the subjects, most of the

434 time, made a mistake and touched the unrewarded No-go target associated with a time out.

435 However, there was still a sign that the subjects tried to override their prepotent response, the

436 mean response latency on a No-go trial $(\mathrm{M} \pm \mathrm{SE}=3123.13 \pm 36.68 \mathrm{~ms}, \mathrm{~N}=20)$ was

437 significantly longer than the one in a Go trial $(\mathrm{M} \pm \mathrm{SE}=2881.81 \pm 91.69 \mathrm{~ms}, \mathrm{~N}=20$, see Fig. 2 ,

438 from the log-transformation of the response latency, likelihood-ratio test, $\chi^{2}(1, N=20)=$

$439600.73, \mathrm{p}<0.001$, see Supplemental materials Table S3). Please refer to Supplemental materials

440 Table S2 and S3 for the effect of the other explanatory variables on the model. These results

441 indicate that the subject had a prepotent response to touch any time of stimulus, but still tried to

442 overcome this dominant response by slowing down their action toward the screen, this task is

443 thus assessing the inhibition of a prepotent action.

\section{Content validity, Reversal learning task}

445 First, we found that the previous task did not influence the subjects' responses as they did not

446 choose the red stimulus for the first trial above the chance level (chance level $=0.5$, mean

447 proportion $=0.53, \mathrm{p}=0.84$ ). There was a significant difference in the mean success in a trial if

448 the rule was the first acquisition or the reversed rule (likelihood-ratio test, $\chi^{2}(1, \mathrm{~N}=20)=5.10$, 
$449 \mathrm{p}=0.02$, see Supplemental materials Table S4 for more details on the other explanatory

450 variables), the probability of success was significantly a little higher in the first rule $(65 \pm 0.97 \%$

451 of success, $\mathrm{N}=20)$, compared to the reversed rule $(63 \pm 0.78 \%$ of success, $\mathrm{N}=20$, see Fig. 2$)$.

452 These results indicate that the acquisition rule was interfering with the learning of the reversed

453 rule, despite this interaction $100 \%$ of the remaining subject still managed to pass the $75 \%$

454 criterion of success for the second rule (see Table 1 for a summary of the main findings).

\section{Temporal repeatability}

\section{Analysis}

457 We wanted to assess the temporal repeatability (also known as test-retest reliability) of the

458 individual's inhibitory performances. For this, we computed, from the response variables

459 (response latency and successful completion of the tasks), scores of inhibitory control. For the

460 Distraction task we computed a Distraction control score, which is the standard method in

461 Stroop task paradigms (as in Allritz, Call \& Borkenau, 2016; Bethell et al., 2016, 2019).

462 Distraction control score represented, for each trial, the difference between the mean response

463 latency in all trials without pictures minus the response latency in each trial. For a trial with a 464 picture, a higher score would indicate better control of a Distraction (a shorter response latency).

465 For the second task, the Go/No-go task, to quantify the individual's ability to inhibit its prepotent 466 action, we calculated the Action control score as the mean percentage of trials when a No-Go 467 was present, and the individual didn't touch it for each session (Verbruggen \& Logan 2008). We 468 took the last 3 sessions of each time point of each animal to have a comparable number of 469 sessions between tasks. A higher score would indicate an individual is better at inhibiting the 470 action. Finally, we calculated a Rule control score (as in Tapp et al., 2003; Wobber and Hare

471 2009), as the difference between the number of trials to reach the criterion of success for the first 
472 rule ( $75 \%$ of correct trials for the whole session) minus the number of trials to reach the same

473 criterion for the reversed rule. A higher score would indicate that an individual is better at

474 inhibiting a previous rule when learning a new one.

475 Once we had these inhibitory control scores, we wanted to assess the temporal repeatability (also

476 known as test-retest reliability) of the individual's inhibitory control scores, i.e. if the rank of the

477 performances of each subjects within the group were consistent over the two time points (as done

478 in the meta-analysis of Cauchoix et al., 2018). We used the repeatability estimates (R) or

479 Intraclass Correlation Coefficient (ICC) which indicates the amount of variation explained by

480 inter-individual variation of performances in the tasks relative to intra-individual variation

481 (developed by Nakagawa and Schielzeth 2010). This estimate accounts for both consistency of

482 performances from test to retest (within-subject change), as well as change in average

483 performance of participants as a group over time (Vaz et al., 2013). This test thus assesses the

484 repeatability of the rank of the subjects' performances within the group between the test and the

485 retest and between contexts. We used the function 'rpt', from the 'rptR' package v.0.9.22 in R

486 (Nakagawa and Schielzeth 2010; Stoffel, Nakagawa \& Schielzeth, 2017; Vaz et al., 2013). We

487 applied a restricted maximum likelihood function (with 1000 bootstrapping and 1000

488 permutations) and the individual identity was specified as a random intercept effect. The

489 appropriate type of data distribution was adjusted in each model depending on the dependent

490 variable under investigation ("Gaussian" for continuous variables, "Binomial” for binomial

491 variables). We checked Gaussian models for normal distribution of the residuals using the

492 function 'qqnorm' from the R package 'car' v3.0-6. An individual's performance was considered

493 as repeatable if the $p$-value from the Likelihood-ratio test was $<0.05$. The decision for the

494 qualification of the R estimates, either low, moderate, or high, was based on the work of 
495 (Cauchoix et al., 2018). In this meta-analysis, regrouping 44 studies across 25 animal species, the 496 authors computed the repeatability of individual cognitive performances. They found out a mean 497 estimate for the temporal repeatability unadjusted of $\mathrm{R}=0.18,95 \% \mathrm{CI}[0.09,0.28]$, the $\mathrm{R}$ 498 adjusted for test order and individual determinants was $\mathrm{R}_{\mathrm{adj}}=0.15,95 \% \mathrm{CI}[0.09,0.21]$. We 499 considered that if $\mathrm{R} \leq 0.1$ the repeatability estimate is low, for $0.1<\mathrm{R} \leq 0.3$, it is moderate and 500 for $\mathrm{R}>0.3$ it is high.

501 Once the (R) estimates were calculated, we also needed to consider the influence of confounding 502 factors on the temporal repeatability estimates. For this we calculated adjusted estimates 503 (estimates that adjust for confounding effects which remove fixed effect variance from the 504 estimate, see Nakagawa and Schielzeth, 2010, Stoffell et al., 2017; as done in Cauchoix et al., 505 2018). Adjusted repeatability can be interpreted as the repeatability given that the level of the 506 confounding factor is known (Nakagawa and Schielzeth, 2010). To calculate these adjusted 507 estimates, we first needed to determine which factors had an effect on the individual's 508 performances by fitting linear mixed models (LMM) and general linear mixed models (GLMM) 509 (we used the same packages as for the content validity). The outcome variables were either the Distraction control score, the Action control score or the Rule control score. As before, we control for two types of confounding factors: individual determinants (age, sex, rank of the 512 individuals, experience with pictures for the Distraction task), and test determinants (type of 513 stimulus, time point, session and trial). Individual's identity was included as a random factor.

514 The full model contained all probable explanatory variables (demographic and task

515 determinants). We used the same model selection as before (see content validity) and the 516 function 'anova' from the R package 'car' v3.0-6 to compare each model and our significant 517 threshold was $\mathrm{p}<0.05$. Then, we calculated the adjusted repeatability, $\mathrm{R}_{\text {adj }}$, by including 
518 confounding effects (identified by comparing GLMMs) into the repeatability function.

519 Uncertainty in estimators was quantified by parametric bootstrapping and significance testing

520 was implemented by likelihood ratio tests with a significance threshold of $\mathrm{p}<0.05$ (Stoffel,

521 Nakagawa \& Schielzeth, 2010). We reported 95\% confidence intervals (CIs) for parameter

522 estimates based on 1000 bootstrapping and 1000 permutations. We reported the result for the

523 adjusted repeatability from the "Link scale approximation".

\section{Results}

525 Temporal repeatability, Distraction task

526 For the Distraction task, the Distraction control score per individual was moderately repeatable

527 between sessions and the two time points $(\mathrm{R}=0.282 \pm 0.095,95 \% \mathrm{CI}[0.093,0.462], \mathrm{p}<0.001)$.

528 When testing for explanatory factors using LMMs, the model with the variables session, time-

529 point and sex as fixed terms best explained the Distraction control score of the subjects

530 (likelihood-ratio test comparing the best fitted model with the null model: $\chi^{2}(5, \mathrm{~N}=21)=$

531 119.61, $\mathrm{p}<0.001$, see Supplemental materials Table S5). Males had a lower Distraction control

532 score (likelihood-ratio test, $\left.\chi^{2}(1, \mathrm{~N}=21)=9.38, \mathrm{p}=0.002\right)$, and this score increased as the

533 number of the session increased (likelihood-ratio test, $\chi^{2}(1, \mathrm{~N}=21)=14.02, \mathrm{p}<0.001$ ) and at

534 time point 2 (likelihood-ratio test, $\left.\chi^{2}(1, \mathrm{~N}=21)=93.14, \mathrm{p}<0.001\right)$. When considering these

535 confounding factors, the adjusted repeatability of the Distraction control score was lower than

536 the unadjusted repeatability $\left(\mathrm{R}_{\mathrm{adj}} \pm \mathrm{SE}=0.128 \pm 0.048,95 \% \mathrm{CI}[0.041,0.241], \mathrm{p}<0.001\right)$ but

537 still repeatable (see Fig. 3). Thus, in this Distraction task, the rank of the subjects' performances

538 within the group was repeatable over the two time points. 


\section{Temporal repeatability, Go/No-go task}

540 For the Go/No-go task, the Action control score per session per individual was highly repeatable

541 between sessions and the two time points $(\mathrm{R}=0.338 \pm 0.105,95 \% \mathrm{CI}[0.120,0.514], \mathrm{p}<0.001)$.

542 When testing for confounding factors using GLMMs, none of the variables had a significant

543 effect on the model of the Action control score of the subjects so the temporal repeatability

544 estimates were not adjusted (likelihood-ratio test comparing the full model with the null model:

$545 \chi^{2}(7, N=20)=6.85, p=0.44$, see Supplemental materials Table S6 and Fig. 3). Thus, in this

546 Go/No-go task, the rank of the subjects' performance within the group was repeatable over the

547 two time points.

\section{Temporal repeatability, Reversal learning task}

549 For the Reversal learning task, the Rule control score per session per individual was highly

550 repeatable between the sessions and the two time points $(\mathrm{R}=0.944 \pm 0.033,95 \% \mathrm{CI}[0.855$,

551 0.981], $\mathrm{p}<0.001)$. When testing for confounding factors using GLMMs, none of the explanatory

552 variables had a significant effect on the models so the temporal repeatability estimates were not

553 adjusted (likelihood-ratio test comparing the full model with the null model: $\chi^{2}(7, N=20)=$

$5543.59, \mathrm{p}=0.61$, see Supplemental materials Table S7 for more details about the other confounding

555 variables). Thus, in this Reversal learning task, the rank of the subjects' performances, within the 556 group, was repeatable over the two time points.

557 To summarize, the rank of the individual performances within the group for inhibitory control 558 scores were consistent over time. While the adjusted temporal repeatability estimates were lower 559 compared to the unadjusted ones, they were still repeatable (see Table 1 for a summary of the 560 main findings). 


\section{Contextual repeatability between each task}

\section{Analysis}

563 Once we had demonstrated the content validity and the temporal repeatability of our

564 measurements, we were able to look at the cross-contextual consistency of the individual's

565 performances between the different tasks. We estimated contextual repeatability of our tasks by

566 comparing individual performances on different tasks that putatively measure inhibitory control

567 (as done in the meta-analysis of Cauchoix et al., 2018). We thus wanted to look at the

568 consistency between subject's performance ranks between each pair of tasks. We use the same

569 repeatability test as before to assess the repeatability of the rank of the subjects' performances

570 within the group between contexts. As before, we used LMMs and GLMMs to look for

571 confounding factors in order to adjust the contextual repeatability when two tasks were analysed.

572 In the models, the inhibitory control score was the dependent variables and one of the 4 types of

573 tasks, the sex, the age, the rank, the session, and the time point were the independent variables.

574 Each score was centred and scaled using the function 'scale' from the package 'base', in R

575 v3.6.3 to allow comparison between the scores of different units. As before, the decision for the

576 qualification of the $\mathrm{R}$ estimates, was either low $(\mathrm{R} \leq 0.1)$, moderate $(0.1<\mathrm{R} \leq 0.3)$, or high ( $\mathrm{R}>$

$577 \quad 0.3)$

\section{Results}

579 The contextual repeatability between the Distraction control score and the Action control score

$580(\mathrm{R}=0.166 \pm 0.067,95 \%$ CI [0.041, 0.305], $\mathrm{p}<0.001)$, between the Distraction control score

581 and the Rule control score $(\mathrm{R}=0.212 \pm 0.085,95 \%$ CI $[0.049,0.38], \mathrm{p}<0.001)$ and between the

582 Action control score and the Rule control score $(\mathrm{R}=0.138 \pm 0.077,95 \% \mathrm{CI}[0.003,0.303], \mathrm{p}=$

583 0.01) were moderate (see Supplemental materials Table S8 for a summary of the unadjusted

584 contextual repeatability for all the inhibitory control scores). 
585 The adjusted contextual repeatability (Table 2 summarizes all the adjusted contextual

586 repeatability estimates), between the Distraction control score and the Action control score when

587 controlling for session and time point, remained repeatable and moderate $\left(\mathrm{R}_{\mathrm{adj}} \pm \mathrm{SE}=0.17 \pm\right.$

$5880.066,95 \%$ CI $[0.045,0.306], \mathrm{p}<0.001$, see Supplemental materials Table S9). However,

589 between the Action control score and the Rule control score when controlling for sex, the

590 performances between the tasks were not repeatable anymore. $\left(\mathrm{R}_{\mathrm{adj}} \pm \mathrm{SE}=0.101 \pm 0.066,95 \%\right.$

591 CI [0.000, 0.24], $\mathrm{p}=0.07$, see Supplemental materials Table S10). Similarly, between

592 Distraction control score and the Rule control score when controlling for sex $\left(\mathrm{R}_{\mathrm{adj}} \pm \mathrm{SE}=0.09 \pm\right.$

$5930.058,95 \%$ CI $[0.000,0.22], \mathrm{p}=0.07$, see Supplemental materials Table S11) the performances

594 between the tasks were not repeatable after adjustments. The other scores did not have any

595 confounding variables, so the contextual estimates were not adjusted.

596 To summarize, we found, for the inhibitory control scores, when adjusted for confounding

597 factors, that the contextual repeatability was only significant between the Distraction task and the

598 Go/No-go (see Table 1 for a summary of the main findings).

\section{Discussion}

600 The aim of this study was to first validate a battery of inhibitory control in non-human primates

601 by assessing the content validity and temporal repeatability of three tasks covering the main

602 domains of inhibitory control. Then, using this battery of tasks, we wanted to investigate the

603 structure of inhibitory control by looking at the contextual consistency of subjects' performances

604 between these tasks. First, we found a response pattern characteristic of inhibitory control in each

605 of the 3 tasks, an indicator of content validity. A prepotent response (an interference from a

606 pictorial distractor, a dominant motoric response, and a pre-learned rule) was inhibited by the

607 subjects to successfully achieve the goal of the task. We then confirmed that the performances of 
608 the subjects were repeatable across 2 time points, thus validating the test-retest reliability of our 609 tasks. Finally, our results gave an insight of the structure of inhibitory control by demonstrating 610 that the individual performances between the Distraction task and the Go/No-go tasks, even after 611 adjustments for confounding factors (session and time point), were also consistent, indicating 612 that these tasks seem to capture the same cognitive process. However, after adjustment, the 613 individual performances between the Reversal learning task and the other tasks of inhibitory 614 control were not consistent, interestingly indicating the absence of a common underlying ability 615 (see Table 1 for a summary of the main findings).

616 The first step in validating a battery of inhibitory control measurement was to demonstrate their 617 content validity. Looking closely at the pattern of response, our results indicated that a prepotent 618 response was generated from the test conditions. In other research studies, using the Reversal 619 learning task and motor inhibition tasks, in dogs (C. familiaris, Bray, MacLean \& Hare 2014; 620 Brucks et al., 2017; Marshall-Pescini, Virányi and Range, 2015; Vernouillet et al., 2018), wolves 621 (Marshall-Pescini, Virányi and Range, 2015) or in pheasants (Phasianus colchicus, van Horik et 622 al., 2018, 2019), the tasks were similarly producing a prepotent response. The same pattern of 623 response was found in the Distraction tasks in non-human primates (Allritz, Call \& Borkenau, 624 2016; Bethell et al., 2016; Landman et al., 2014). Unfortunately, this inhibitory pattern of 625 response is rarely systematically investigated. For example, the cylinder task has been used in a 626 large comparative study, of more than 36 species, to draw conclusions about the evolution of 627 inhibitory control (Maclean et al., 2014). However, the content validity of this task has been 628 recently challenged (Kabadayi, Bobrowicz \& Osvath, 2018; Shaw \& Schmelz, 2017). Thus, to 629 first demonstrate the content validity of a cognitive task seems a crucial step in order to both 630 justify its use and draw evolutive conclusions from it. 
631 Another critical step was to make sure that these tasks were repeatable over time. A lack of

632 temporal repeatability can be detrimental in subsequent assessment of validity (Friedman \&

633 Miyake, 2017; Paap \& Oliver, 2016). As expected, we found moderate and significant, temporal

634 estimates. Our mean estimate of $\mathrm{R}=0.40$ is higher than mean estimates found in common

635 cognitive tasks in animals (from the meta-analysis of Cauchoix et al., 2018, the mean estimate is

$636 \mathrm{R}=0.18)$. In the animal cognition literature, inhibitory control temporal estimates are ranging

637 from very low $(\mathrm{R}=0.012)$ to very high values $(\mathrm{R}=0.975)$ (Ashton et al., 2018; Cauchoix et al.,

6382017,2018 ); our range of estimates is similarly diverse (from $\mathrm{R}=0.128$ to 0.944 ) but still

639 significant as expected. The confirmation of the temporal repeatability of any cognitive

640 measurements seems also a crucial step before establishing the validity of any tasks.

641 Once we established the content validity and temporal repeatability of our measurements, we

642 evaluated the cross-contextual consistency of the inhibitory control tasks. We first found that all

643 the unadjusted estimates were significant. These results were similar to the ones obtained in

644 Australian magpies which obtained a Spearman rank order correlation estimate of $\mathrm{r}=0.433$

645 between the cylinder task and the reversal learning task (Ashton et al., 2018). Similarly, in a

646 large interspecies study, Maclean et al. (2014), found that performance on the A not B and

647 cylinder task was strongly correlated $(r=0.53)$. However, using the data from the study of

648 Maclean et al. (2014), looking from an individual difference perspective, Völter and colleagues

649 (2018), did not find any correlation between the inhibitory control tasks. When controlling for

650 confounding factors, the adjusted repeatability between the Distraction task and the Go/No-go

651 task were lower but still significant, this could indicate a common underlying ability. The

652 decrease in the value of the adjusted contextual estimates were similar to the one found in

653 Cauchoix and colleagues (2018). This could be because the confounding factors, that vary 
654 between individuals, reduce the between-group variance and thus the repeatability (Nakagawa

655 and Schielzeth, 2010). These results confirm the importance of controlling for confounding

656 factors when assessing contextual repeatability.

657 Surprisingly, the adjusted contextuality estimates between the Reversal learning task and the two 658 other tasks of inhibitory control were not significant. It seems that the Distraction tasks

659 (inhibition of a distractor) and the Go/No-go (inhibition of an impulsive action), share a common 660 underlying inhibitory ability, i.e. to inhibit an impulsive, unconscious response to a stimulus.

661 However, between the Reversal learning task (inhibition of a cognitive set) and the other tasks no 662 clear pattern emerges that would support the notion of a common cognitive ability. These results 663 reproduce the same pattern found in human research, with correlation between two inhibition664 related functions: the "resistance to distractor interference" (similar to our definition of 665 Distraction inhibition) and "prepotent resistance interference" (similar to our definition of action 666 inhibition) but not with "resistance to proactive interference" (similar to our definition of 667 cognitive set inhibition; Friedman \& Miyake, 2004). Interestingly, similar results were also 668 demonstrated in several studies in canids, specifically designed to understand the structure of 669 inhibitory control. Authors found a lack of correlation between the detour task or cylinder task 670 (inhibition of an impulsive action) and the A-not-B task (inhibition of a cognitive set; Bray, 671 MacLean \& Hare 2014; Brucks et al., 2017; Fagnani et al., 2016; Marshall-Pescini, Virányi and

672 Range, 2015; Vernouillet et al., 2018). Thus, the inhibition of an external distractor and the 673 inhibition of a prepotent motor response seem to share the same underlying inhibitory ability but 674 not the inhibition of a previously learned rule. It is possible that the inhibition of an impulsive 675 and prepotent, stimulus driven response, relies more on cognitively low demanding construct, 676 such as a simple bottom-up inhibitory control function (Nigg, 2017). On the contrary, in the 
677 learning of a new rule, it could be required, in addition to inhibitory control, to employ a higher

678 deliberate cognitive ability, a top-down function, relying on mental representations (e.g. working

679 memory or set shifting, Dillion, 2007, Nigg, 2017). These results are at odds with the hypothesis

680 that all three inhibition-related functions are measuring some common ability. Thus, our results

681 provide a new insight in favour of the multifaceted structure of inhibitory control in a non-human

682 primate. It would be difficult to broaden our interpretation to other species because of the

683 potential species-specific differences in the nature of inhibitory control. Inhibitory control could

684 be a general construct in some taxa but a family of independent components in other taxa.

685 Understanding the structure of inhibitory control is particularly crucial as impairments in

686 inhibitory control have been associated with several psychopathologies. For instance, in children

687 suffering from ADHD, it is still unclear if it is inhibitory control as a general ability which is

688 impaired or only some independent components (Gaultney, 1999; Nigg 2001). Consistent with

689 this last view, there is some evidence that individuals with ADHD are impaired on tasks

690 measuring response inhibition, whereas it remains unclear if these patients are also impaired in

691 cognitive inhibition tasks (Gaultney et al., 1999; Nigg, 2001). However, we need to be cautious

692 in the comparison of results between studies using different types of contextual validity analysis.

693 On one hand, some studies used correlations analysis (Bray, MacLean \& Hare, 2014; Duckworth

694 \& Kern, 2011; Fagnani et al., 2016; Vernouillet et al., 2018); which focuses on the strength of

695 association between two means of performances (Liu et al., 2016; McGraw \& Wong, 1996). On

696 the other hand, some authors used repeatability estimates or intraclass correlation based on

697 variance analysis (Ashton et al., 2018; Cauchoix et al., 2018; Shaw, 2017). Unlike correlation, in

698 this agreement analysis, the emphasis is on the degree of concordance between individual

699 performances (Koo \& Li, 2016; Liu et al., 2016; McGraw \& Wong, 1996). Furthermore, 
700 repeatability analysis, unlike correlation, allowed researchers to control for confounding factors

701 (such as individual or temporal determinants, Nakagawa \& Schielzeth, 2010; Vaz et al., 2013). It

702 is thus possible to have two sets of scores that are highly correlated, but not repeatable (Zaki et

703 al., 2013). We can thus look for patterns between results of different studies, but we should be

704 careful in making stronger assertions.

705 Moreover, the interpretation of the repeatability estimates must be drawn carefully because it

706

707

708

709

710

711

712

713

714

715

716

717

718

719

720

721

722 assumes that inhibitory control performances on each cognitive test is independent of other idiosyncratic task demands (e.g., learning, problem solving), or individual characteristics (e.g. motivation, personality traits; see Cauchoix et al., 2018; Griffin, Guillette \& Healy, 2015;

Kabadayi, Bobrowicz \& Osvath, 2018). For example, motivation to get a reward is an important confounding factor. If the reward is visible it strongly affects the subject's ability to inhibit its response (Brucks et al., 2017; Kabadayi, Bobrowicz \& Osvath, 2018). As in the inhibitory control field, this task impurity problem is particularly strong, we should be careful to label any common factor inhibitory control (or a suite of inhibitory control abilities) as it remains unclear what the shared variance represents (Friedman \& Miyake, 2004; Völter et al., 2018). These results are in line with the claim that the nature of inhibitory control is not unitary but are more likely a collection of sub-components intertwined with other cognitive processes that may or may not be engaged on specific contexts that require inhibition (Beran, 2018; Diamond, 2013; Dillon \& Pizzagalli, 2007; Friedman \& Miyake, 2004; Nigg, 2017).

To minimize this task impurity problem, a measurement of another influencing construct, e.g. a memory task (known to tap mostly in memory ability) should ideally be incorporated in a battery of inhibitory control tasks. In this way, researchers could compare the performances in the inhibitory control tasks and the memory task to try to disentangle the different constructs

Peer) reviewing PDF | (2021:09:65913:1:2:NEW 12 Dec 2021) 
723 involved. In addition, we could incorporate measures of behaviours characteristic of other

724 involved constructs (Cauchoix et al., 2018). For example, an eye tracker could be used to record

725 the rate of gaze switching direction between stimuli to control for attention. Similarly, the

726 occurrence of facial expression or body scratches could be used to assess the emotional arousal

727 or stress of the subjects. Once the effect of confounding factors is clearer, researchers could

728 focus on a broader approach of inhibitory control looking at the factors influencing its evolution,

729 such as species' social life or ecology.

730 Another limitation we faced, common when working with primates, is the low sample size which

731 might decrease the power of our analysis (Koo \& Li, 2016; Paap \& Oliver, 2016; Völter et al.,

732 2018). Moreover, our results are potentially only representative of one sample of one population

733 of captive rhesus macaques. We hope that this study will be replicated on a larger sample size,

734 using for instance, a large-scale collaborative project across laboratories or field sites (e.g.

735 ManyPrimates et al., 2019).

\section{Conclusion}

737 To summarize, we have developed a battery of touchscreen tasks of inhibitory control which demonstrated content validity and temporal repeatability. We showed a consistency of

739 performance between the inhibition of a Distraction and the inhibition of an action, representing

740 a response-driven basic form of inhibition, this was not found for inhibition of a pre-learned rule.

741 This task battery provides us with a new insight into the structure of inhibitory control in a non-

742 human primate. This ability seems to be composed of intertwined sub-processes, which might or

743 might not rely on other cognitive constructs. Inhibitory control could be divided in sub-

744 components, with on one hand, a cognitively low demanding process involving the inhibition of

745 a prepotent, stimulus driven response and on another hand a more controlled, deliberate 
746 inhibition of a mental state. It seems crucial that future studies focus on a better understanding of

747 this ability given the importance of inhibition-related processes in successful day-to-day living.

\section{Acknowledgements}

749 We are grateful to Margot Moniot and Elen Stanton for their help in collecting the data. Thank

750 you to Florent Le Moël and Alexandre Montlibert for their help in creating the MATLAB scripts.

751 Many thanks to Dr. Claire Witham and all the caretakers from the MRC, UK for their help in

752 coordinating in situ the collection of the data. Thank you to Dr. Claire Witham for letting us use

753 her pictures of the macaques.

754

755

756

757

758

759

760

761

762

763

764

765

766

767

768

769

770

771

772

773

774

775

776

\section{References}

Allritz, M., Call, J., and Borkenau, P. 2016. How chimpanzees (Pan troglodytes) perform in a modified emotional Stroop task. Animal Cognition 19(3):435-449 DOI: 10.1007/s10071015-0944-3

Amici, F., Aureli, F., and Call, J. 2008. Fission-fusion dynamics, behavioral flexibility, and inhibitory control in primates. Current Biology 18(18):1415-1419 DOI: 10.1016/j.cub.2008.08.020

Aron, A. R. 2007. The neural basis of inhibition in cognitive control. The Neuroscientist, 13(3):214-228 DOI: $10.1177 / 1073858407299288$

Ashton, B. J., Ridley, A. R., Edwards, E. K., and Thornton, A. 2018. Cognitive performance is linked to group size and affects fitness in Australian magpies. Nature 554:7692 DOI: 10.1038 /nature25503

Banich, M. T. 2009. Executive function: the search for an integrated account. Current Directions in Psychological Science 18(2):89-94 DOI: 10.1111/j.14678721.2009.01615.x

Bar-Haim, Y., Lamy, D., Pergamin, L., Bakermans-Kranenburg, M. J., and van IJzendoorn, M. H. 2007. Threat-related attentional bias in anxious and nonanxious individuals: A meta-analytic study. Psychological Bulletin 133(1):1-24 DOI: 10.1037/00332909.133.1.1

Bates, D., Mächler, M., Bolker, B., and Walker, S. 2015. Fitting Linear Mixed-Effects Models Using lme4. Journal of Statistical Software 67(1):1-48 DOI: 10.18637/jss.v067.i01

Bell, A. M., Hankison, S. J., and Laskowski, K. L. 2009. The repeatability of behaviour: a meta-analysis. Animal behaviour 77(4):771-783 DOI: 10.1016/j.anbehav.2008.12.022 
Beran, M. 2018. Are Animal Tests of Self-Control All Measuring the Same Thing? In: Beran, M. (ed). Self-Control in Animals and People, pp.253-270. Academic Press DOI: 10.1016/B978-0-12-812508-3.00012-8.

Beran, M. J., and Hopkins, W. D. 2018. Self-control in chimpanzees relates to general intelligence. Current Biology 28(4):574-579 DOI: 10.1016/j.cub.2017.12.043

Bethell, E. J., Holmes, A., MacLarnon, A., and Semple, S. 2016. Emotion Evaluation and Response Slowing in a Non-Human Primate: New Directions for Cognitive Bias Measures of Animal Emotion? Behavioral sciences 6(1):2 DOI: 10.3390/bs6010002

Biro, P. A., and Stamps, J. A. 2015. Using repeatability to study physiological and behavioural traits: ignore time-related change at your peril. Animal Behaviour 105: 223-230 DOI: 10.1016/j.anbehav.2015.04.008

Bond, A. B., Kamil, A. C., and Balda, R. P. 2007. Serial reversal learning and the evolution of behavioral flexibility in three species of North American corvids (Gymnorhinus cyanocephalus, Nucifraga columbiana, Aphelocoma californica). Journal of Comparative Psychology 121(4):372-379 DOI: 10.1037/0735-7036.121.4.372

Bray, E. E., MacLean, E. L., and Hare, B. A. 2014. Context specificity of inhibitory control in dogs. Animal Cognition 17(1):15-31 DOI: 10.1007/s10071-013-0633-z

Brucks, D., Marshall-Pescini, S., Wallis, L. J., Huber, L., and Range, F. 2017. Measures of dogs' inhibitory control abilities do not correlate across tasks. Frontiers in psychology 8:849 DOI: $10.3389 /$ fpsyg.2017.00849

Byrne, R. W., \& Bates, L. A. 2007. Sociality, Evolution and Cognition. Current Biology 17(16):714-723 DOI: 10.1016/j.cub.2007.05.069

Cauchoix, M., Chow, P. K. Y., van Horik, J. O., Atance, C. M., Barbeau, E. J., BarraganJason, G., Bize, P., Boussard, A., Buechel, S. D., Cabirol, A., Cauchard, L., Claidière,N., Dalesman, S., Devaud, J. M., Didic, M., Doligez, B., Fagot, J., Fichtel, C., Henke-Von Der Malsburg, J., ... Morand-Ferron, J. 2018. The repeatability of cognitive performance: A meta-analysis. Philosophical Transactions of the Royal Society B: Biological Sciences 373(1756) DOI: 10.1098/rstb.2017.0281

Cauchoix, M., Hermer, E., Chaine, A. S., and Morand-Ferron, J. 2017. Cognition in the field: Comparison of reversal learning performance in captive and wild passerines. Scientific Reports 7(1) DOI: 10.1038/s41598-017-13179-5

Cronin, K. A., Jacobson, S. L., Bonnie, K. E., and Hopper, L. M. 2017. Studying primate cognition in a social setting to improve validity and welfare: A literature review highlighting successful approaches. PeerJ 2017(8):e3649 DOI: 10.7717/peerj.3649

David, H. A. 1987. Ranking from unbalanced paired-comparison data. Biometrika 74(2):432436 DOI: $10.2307 / 2336160$

Dempster, F.N., and Corkill, A.J. 1999. Interference and inhibition in cognition and behavior: unifying themes for educational psychology. Educational Psychology Review 11:1-88 DOI: $10.1023 / \mathrm{A}: 1021992632168$ 
816

Diamond, A. 2013. Executive functions. Annual Review of Psychology 64:135-168 DOI: 10.1146/annurev-psych-113011-143750

Dillon, D. G., and Pizzagalli, D. A. 2007. Inhibition of action, thought, and emotion: a selective neurobiological review. Applied and Preventive Psychology: Journal of the American Association of Applied and Preventive Psychology 12(3):99-114 DOI: 10.1016/j.appsy.2007.09.004

Duckworth, A. L., and Kern, M. L. 2011. A meta-analysis of the convergent validity of selfcontrol measures. Journal of Research in Personality 45(3):259-268 DOI: 10.1016/J.JRP.2011.02.004

Duque, J. F., and Stevens, J. R. 2017. Cylinder Task. In: Vonk, J., and Shackelford, T. (eds). Encyclopedia of Animal Cognition and Behavior. Springer, Cham 15. DOI: 10.1007/9783-319-47829-6_1608-1

Estep, D. Q., Nieuwenhuijsen, K., Bruce, K. E., De Neef, K. J., Walters III, P. A., Baker, S. C., \& Slob, A. K. 1988. Inhibition of sexual behaviour among subordinate stumptail macaques, Macaca arctoides. Animal behaviour 36(3):854-864 DOI: 10.1016/S00033472(88)80168-4

Fagnani, J., Barrera, G., Carballo, F., and Bentosela, M. 2016. Is previous experience important for inhibitory control? A comparison between shelter and pet dogs in A-not-B and cylinder tasks. Animal Cognition 19(6):1165-1172 DOI: 10.1007/s10071-016-1024-z

Fazio, R. H. 1990. A practical guide to the use of response latency in social psychological research. Research methods in personality and social psychology 11:74-97.

Friedman, N. P., and Miyake, A. 2004. The Relations Among Inhibition and Interference Control Functions: A Latent-Variable Analysis. Journal of Experimental Psychology: General 133(1):101-135 DOI: 10.1037/0096-3445.133.1.101

Friedman, N. P., and Miyake, A. 2017. Unity and diversity of executive functions: Individual differences as a window on cognitive structure. Cortex; a Journal Devoted to the Study of the Nervous System and Behavior 86:186-204 DOI: 10.1016/j.cortex.2016.04.023

Gärtner, A., and Strobel, A. 2019. Individual differences in inhibitory control: A latent variable analysis. PsyArXiv DOI: 10.31234/osf.io/gnhmt

Gaultney, J. F., Kipp, K., Weinstein, J., \& McNeill, J. 1999. Inhibition and mental effort in attention deficit hyperactivity disorder. Journal of Developmental and Physical Disabilities 11(2):105-114 DOI: 10.1023/A:1021890919601

Gazes, R. P., Brown, E. K., Basile, B. M., \& Hampton, R. R. 2013. Automated cognitive testing of monkeys in social groups yields results comparable to individual laboratorybased testing. Animal cognition 16(3):445-458 DOI: 10.1007/s10071-012-0585-8

Griffin, A.S., Guillette, L.M., and Healy, S.D. 2015. Cognition and personality: an analysis of an emerging field. Trends in ecology and evolution 30(4):207-14 DOI: 10.1016/j.tree.2015.01.012 
854

855

856

857

858

859

860

861

862

863

864

865

866

867

868

869

870

871

872

873

874

875

876

877

878

879

880

881

882

883

884

885

886

887

888

889

890

891

892

Harald Baayen, R., and Milin, P. 2010. Analyzing reaction times. International Journal of Psychological Research 3(2):12 DOI: 10.21500/20112084.807

Harrison, X. A., Donaldson, L., Correa-Cano, M. E., Evans, J., Fisher, D. N., Goodwin, C. E. D., Robinson, B. S., Hodgson, D. J., and Inger, R. 2018. A brief introduction to mixed effects modelling and multi-model inference in ecology. PeerJ 2018(5) DOI: 10.7717/peerj.4794

Haynes, S. N., Richard, D., \& Kubany, E. S. 1995. Content validity in psychological assessment: A functional approach to concepts and methods. Psychological assessment 7(3):238 DOI: $10.1037 / 1040-3590.7 .3 .238$

Herrmann, E., Call, J., Hernández-Lloreda, M. V., Hare, B., and Tomasello, M. 2007. Humans have evolved specialized skills of social cognition: The cultural intelligence hypothesis. Science, 317(5843):1360-1366 DOI: 10.1126/science. 1146282

Herrmann, E., Hare, B., Call, J., \& Tomasello, M. 2010. Differences in the cognitive skills of bonobos and chimpanzees. PloS one 5(8):e12438 DOI: 10.1371/journal.pone.0012438

Hinde, R. A., and Rowell, T. E. 1962. Communication by postures and facial expressions in the rhesus monkey (Macaca mulatta). Proceedings of the Zoological Society of London 138(1):1-21 DOI: 10.1111/j.1469-7998.1962.tb05684.x

Hopper, L. M., Allritz, M., Egelkamp, C. L., Huskisson, S. M., Jacobson, S. L., Leinwand, J. G., \& Ross, S. R. 2021. A Comparative Perspective on Three Primate Species' Responses to a Pictorial Emotional Stroop Task. Animals 11(3):588 DOI: 10.3390/ani11030588

Isaac, L., Vrijsen, J. N., Eling, P., van Oostrom, I., Speckens, A., and Becker, E. S. 2012. Verbal and facial-emotional stroop tasks reveal specific attentional interferences in sad mood. Brain and Behavior 2(1):74-83 DOI: 10.1002/brb3.38

Jacobson, S. L., Kwiatt, A. C., Ross, S. R., and Cronin, K. A. 2018. The effects of cognitive testing on the welfare of zoo-housed Japanese macaques (Macaca fuscata). Applied Animal Behaviour Science 212:90-97 DOI: 10.1016/j.applanim.2018.12.014

Jelbert, S. A., Taylor, A. H., and Gray, R. D. 2016. Does absolute brain size really predict selfcontrol? Hand-tracking training improves performance on the A-not-B task. Biology letters 12(2):20150871 DOI: 10.1098/rsbl.2015.0871

Johnson-Ulrich L, Holekamp KE. 2020 Group size and social rank predict inhibitory control in spotted hyaenas. Animal Behaviour 160:157-168 DOI: 10.1016/j.anbehav.2019.11.020

Kabadayi, C., Bobrowicz, K., and Osvath, M. 2018. The detour paradigm in animal cognition. Animal Cognition 21(1):21-35 DOI: 10.1007/s10071-017-11520

Kangas, B. D., and Bergman, J. 2017. Touchscreen technology in the study of cognitionrelated behavior. Behavioural Pharmacology 28(8):623-629 DOI: 10.1097/FBP.0000000000000356

Koo, T. K., and Li, M. Y. 2016. A guideline of selecting and reporting intraclass correlation coefficients for reliability research. Journal of Chiropractic Medicine 15(2):155-163 DOI: $10.1016 /$ j.jcm.2016.02.012

PeerJ reviewing PDF | (2021:09:65913:1:2:NEW 12 Dec 2021) 
893

894

895

896

897

898

899

900

901

902

903

904

905

906

907

908

909

910

911

912

913

914

915

916

917

918

919

920

921

922

923

924

925

926

927

928

929

930

931

932

Lacreuse A., Russell, J. L., Hopkins, W. D., \& Herndon, J. G. 2014. Cognitive and motor aging in female chimpanzees. Neurobiology of aging 35(3):623-632 DOI: 10.1016/j.neurobiolaging.2013.08.036

Landman, R., Sharma, J., Sur, M., and Desimone, R. 2014. Effect of distracting faces on visual selective attention in the monkey. Proceedings of the National Academy of Sciences of the United States of America 111(50):18037-18042 DOI: 10.1073/pnas.1420167111

Lauwereyns, J., Koizumi, M., Sakagami, M., Hikosaka, O., Kobayashi, S., \& Tsutsui, K. I. 2000. Interference from irrelevant features on visual discrimination by macaques (Macaca fuscata): a behavioral analogue of the human Stroop effect. Journal of Experimental Psychology: Animal Behavior Processes 26(3): 352 DOI: 10.1037//00977403.26.3.352Lindsay DR, Dunsmore DG, Williams JD, Syme GJ 1976) Audience effects on the mating behaviour of rams. Animal Behaviour 24:818-821 DOI: 10.1016/S0003-3472(76)80012-7

Lindsay, D. S. 2015. Replication in Psychological Science. Psychological Science 26(12):18271832 DOI: $10.1177 / 0956797615616374$

Liu, J., Tang, W., Chen, G., Lu, Y., Feng, C., and Tu, X. M. 2016. Correlation and agreement: overview and clarification of competing concepts and measures. Shanghai Arch Psychiatry 28(2):115-120 DOI: 10.11919/j.issn.1002-0829.216045

Loyant, L., Waller, B. M., Micheletta, J., \& Joly, M. 2021. Heterogeneity of performances in several inhibitory control tasks: male rhesus macaques are more easily distracted than females. Royal Society Open Science, 8(11):211564 DOI: 10.1098/rsos.211564

MacLean, E. L., Hare, B., Nunn, C. L., Addessi, E., Amici, F., Anderson, R. C., Aureli, F., Baker, J. M., Bania, A. E., Barnard, A. M., Boogert, N. J., Brannon, E. M., Bray, E. E., Bray, J., Brent, L. J., Burkart, J. M., Call, J., Cantlon, J. F., Cheke, L. G., Clayton, N. S., ... Zhao, Y. 2014. The evolution of self-control. Proceedings of the National Academy of Sciences of the United States of America 111(20):E2140-E2148 DOI: 10.1073/pnas.1323533111

MacLean, E. L., Herrmann, E., Suchindran, S., \& Hare, B. 2017. Individual differences in cooperative communicative skills are more similar between dogs and humans than chimpanzees. Animal Behaviour 126:41-51 DOI: 10.1016/j.anbehav.2017.01.005

MacLeod, C. M. 2007. The concept of inhibition in cognition. In: D. S. Gorfein and C. M. MacLeod (ed). Inhibition in cognition, American Psychological Association, 3-23 DOI: $10.1037 / 11587-001$

Many Primates, Altschul, D., Beran, M. J., Bohn, M., Caspar, K., Fichtel, C., Försterling, M., Grebe, N., Hernandez-Aguilar, R. A., Kwok, S. C., Rodrigo, A. M., Proctor, D., SanchezAmaro, A., Simpson, E., Szabelska, A., Taylor, D., Mescht, J. van der, Völter, C., and Watzek, J. 2019. Collaborative open science as a way to reproducibility and new insights in primate cognition research. Japanese Psychological Review 62(3):205-220 DOI: $10.31234 /$ osf.io/8w7zd

Peer] reviewing PDF | (2021:09:65913:1:2:NEW 12 Dec 2021) 
933
Marshall-Pescini, S., Virányi, Z., and Range, F. 2015. The effect of domestication on inhibitory control: wolves and dogs compared. PloS one 10(2):e0118469 DOI: 10.1371/journal.pone.0118469

McGraw, K. O., and Wong, S. P. 1996. Forming inferences about some intraclass correlation coefficients. Psychological Methods 1(1):30-46 DOI: 10.1037/1082-989X.1.1.30

McKenna, F. P., and Sharma, D. 2004. Reversing the emotional Stroop effect reveals that it is not what it seems: the role of fast and slow components. Journal of Experimental Psychology: Learning, Memory, and Cognition 30(2):382-392 DOI: 10.1037/02787393.30.2.382

Miller, R., Boeckle, M., Jelbert, S. A., Frohnwieser, A., Wascher, C., and Clayton, N. S. 2019. Self-control in crows, parrots and nonhuman primates. Wiley interdisciplinary reviews. Cognitive science 10(6):e1504 DOI: 10.1002/wcs.1504

Miyake, A., Friedman, N. P., Emerson, M. J., Witzki, A. H., Howerter, A., and Wager, T. D. 2000. The unity and diversity of executive functions and their contributions to complex "frontal lobe" tasks: a latent variable analysis. Cognitive Psychology 41(1):49-100 DOI: 10.1006/COGP.1999.0734

Nakagawa, S., and Schielzeth, H. 2010. Repeatability for Gaussian and non-Gaussian data: a practical guide for biologists. Biological reviews of the Cambridge Philosophical Society 85(4):935-56 DOI: 10.1111/j.1469-185X.2010.00141.x

Nigg, J. T. 2000. On inhibition/disinhibition in developmental psychopathology: views from cognitive and personality psychology and a working inhibition taxonomy. Psychological bulletin 126(2):220 DOI: 10.1037/0033-2909.126.2.220

Nigg, J. T. 2017. Annual Research Review: On the relations among self-regulation, selfcontrol, executive functioning, effortful control, cognitive control, impulsivity, risktaking, and inhibition for developmental psychopathology. Journal of Child Psychology and Psychiatry and Allied Disciplines 58(4):361-383 DOI: 10.1111/jcpp.12675

Paap, K. R., and Oliver, S. 2016. The role of test-retest reliability in measuring individual and group differences in executive functioning. Journal of Neuroscience Methods 274:81-93 DOI: $10.1016 /$ j.jneumeth.2016.10.002

Paul ES, Harding EJ, Mendl M. 2005. Measuring emotional processes in animals: The utility of a cognitive approach. Neuroscience Biobehavioral Reviews 29:469-491DOI: 10.1016/j.neubiorev.2005.01.002

R Core Team. 2019. A language and environment for statistical computing. R Foundation for Statistical Computing, Vienna, Austria. URL http://www.R-project.org/

Radel, R., Gruet, M., and Barzykowski, K. 2019. Testing the ego-depletion effect in optimized conditions. PLoS One 14(3):e0213026. DOI:10.1371/journal.pone.0213026

Rana, D.K., and Rao, S.L. 2013. Development and standardization of tests for the measurement of inhibition. Delhi Psychiatry Journal 16(1):90

Peer) reviewing PDF | (2021:09:65913:1:2:NEW 12 Dec 2021) 
971

Rathke, E. M., \& Fischer, J. 2020. Differential ageing trajectories in motivation, inhibitory control and cognitive flexibility in Barbary macaques (Macaca sylvanus). Philosophical Transactions of the Royal Society B 375(1811):20190617 DOI: 10.1098/rstb.2019.0617

Rayburn-Reeves, R. M., James, B. T., \& Beran, M. J. 2017. Within-session reversal learning in rhesus macaques (Macaca mulatta). Animal cognition 20(5):975-983 DOI: 10.1007/s10071-017-1117-3Reader, S. M., and Laland, K. N. 2002. Social intelligence, innovation, and enhanced brain size in primates. Proceedings of the National Academy of Sciences of the United States of America 99(7):4436-4441 DOI: 10.1073/pnas.062041299

Sass SM, Heller W, Stewart JL, Silton RL, Edgar JC, Fisher JE, Miller GA. 2010) Time course of attentional bias in anxiety: emotion and gender specificity. Psychophysiology 47:247-259 DOI: 10.1111/j.1469-8986.2009.00926.x

Shaw, R. C. 2017. Testing cognition in the wild: factors affecting performance and individual consistency in two measures of avian cognition. Behavioural Processes 134:31-36 DOI: 10.1016/j.beproc.2016.06.004

Shaw, R.C., and Schmelz, M. 2017. Cognitive test batteries in animal cognition research: evaluating the past, present and future of comparative psychometrics. Animal Cognition 20:1003-1018 DOI: $10.1007 / \mathrm{s} 10071-017-1135-1$

Stoffel, M. A., Nakagawa, S., and Schielzeth, H. 2017. rptR: repeatability estimation and variance decomposition by generalized linear mixed-effects models. Methods in Ecology and Evolution 8(11): 1639-1644 DOI: 10.1111/2041-210X.12797

Stroop, J. R. (1935. Studies of interference in serial verbal reactions. Journal of Experimental Psychology 18(6): 643-662 DOI: 10.1037/h0054651

Tapp, P. D., Siwak, C. T., Estrada, J., Head, E., Muggenburg, B. A., Cotman, C. W., and Milgram, N. W. 2003. Size and reversal learning in the beagle dog as a measure of executive function and inhibitory control in aging. Learning and Memory 10(1): 64-73 DOI: $10.1101 / 1 m .54403$

Thierry, B. 2000. Covariation of conflict management patterns across macaque species. In: F. Aureli, F. de Waal (ed). Natural conflict resolution, University of California Press, 106128.

Thomas, S., Rao, S. L., and Devi, B. I. 2016. Standardization of tests of attention and inhibition. Indian Journal of Psychological Medicine 38(4): 320-325 DOI: 10.4103/02537176.185959

van Horik, J. O., and Madden, J. R. 2016. A problem with problem solving: motivational traits, but not cognition, predict success on novel operant foraging tasks. Animal Behaviour 114:189-198 DOI: 10.1016/j.anbehav.2016.02.006

van Horik, J. O., Beardsworth, C. E., Laker, P. R., Langley, E. J. G., Whiteside, M. A., and Madden, J. R. 2019. Unpredictable environments enhance inhibitory control in pheasants. Animal Cognition 22(6): 1105-1114 DOI: 10.1007/s10071-019-01302-0 
1009

1010

1011

1012

1013

1014

1015

1016

1017

1018

1019

1020

1021

1022

1023

1024

1025

1026

1027

1028

1029

1030

1031

1032

1033

1034

1035

1036

1037

1038

1039

1040

1041

1042

1043

1044

1045

1046

van Horik, J.O., Langley, E.J., Whiteside, M.A., Laker, P.R., Beardsworth, C.E., and Madden, J.R. 2018. Do detour tasks provide accurate assays of inhibitory control? Proceedings of the Royal Society B: Biological Sciences 285 DOI: 10.1098/rspb.2018.0150

Vardanjani, M. M., Ghasemian, S., Sheibani, V., \& Mansouri, F. A. 2021. The Effects of Emotional Stimuli and Oxytocin on Inhibition Ability and Response Execution in Macaque Monkeys. Behavioural Brain Research 113409 DOI: 10.1016/j.bbr.2021.113409

Vaz, S., Falkmer, T., Passmore, A. E., Parsons, R., and Andreou, P. 2013. The case for using the repeatability coefficient when calculating test-retest reliability. PLoS ONE 8(9) DOI: 10.1371/journal.pone.0073990

Verbruggen, F., and Logan, G. D. 2008. Response inhibition in the stop-signal paradigm. Trends in Cognitive Sciences 12(11): 418-424 DOI: 10.1016/j.tics.2008.07.005

Vernouillet, A. A. A., Stiles, L. R., Andrew McCausland, J., and Kelly, D. M. 2018. Individual performance across motoric self-regulation tasks are not correlated for pet dogs. Learning and Behavior 46(4): 522-536 DOI: 10.3758/s13420-018-0354-X

Völter, C. J., Tinklenberg, B., Call, J., and Seed, A. M. 2018. Comparative psychometrics: establishing what differs is central to understanding what evolves. Philosophical transactions of the Royal Society of London. Series B, Biological sciences 373(1756): 20170283 DOI: $10.1098 /$ rstb.2017.0283

Washburn, D. A. (1994. Stroop-like effects for monkeys and humans: Processing speed or strength of association? Psychological Science 5(6): 375-379 DOI: 10.1111/j.14679280.1994.tb00288.x

Washburn, D. A., Harper, S., and Rumbaugh, D. M. (1994. Computer-task testing of rhesus monkeys (Macaca mulatta) in the social milieu. Primates 35(3): 343-351 DOI: 10.1007/BF02382730

Whelan, R. 2008. Effective analysis of reaction time data. Psychological Record 58(3): 475482 DOI: 10.1007/BF03395630

Williams, J. M. G., Mathews, A., and MacLeod, C. (1996. The emotional Stroop task and psychopathology. Psychological Bulletin 120(1): 3-24 DOI: 10.1037/0033-2909.120.1.3

Willoughby, M., and Blair, C. 2011. Test-retest reliability of a new executive function battery for use in early childhood. Child Neuropsychology 17(6): 564-579 DOI: 10.1080/09297049.2011.554390

Wobber, V., Herrmann, E., Hare, B., Wrangham, R., \& Tomasello, M. 2014. Differences in the early cognitive development of children and great apes. Developmental psychobiology 56(3): 547-573 DOI: 10.1002/dev.21125

Wöstmann, N. M., Aichert, D. S., Costa, A., Rubia, K., Möller, H.-J., and Ettinger, U. 2013. Reliability and plasticity of response inhibition and interference control. Brain and Cognition 81(1): 82-94 DOI: 10.1016/J.BANDC.2012.09.010 
1047 Zaki, R., Bulgiba, A., Nordin, N., and Ismail, N. A. 2013. A systematic review of statistical 1048

1049 methods used to test for reliability of medical instruments measuring continuous variables. Iranian Journal of Basic Medical Sciences 16(6): 803-807 DOI:

1050 10.22038/ijbms.2013.998 


\section{Figure 1}

Schematic representation of the touchscreen tasks procedures and aims of the study.

The Distraction task (inhibition of a distraction), the Go/No-go task (inhibition of an action) and the Reversal learning task (inhibition of a cognitive set) are presented. The aims of the study are also presented: 1 . Content validity, 2 . Temporal repeatability (with timeline) and 3 . Contextual repeatability.

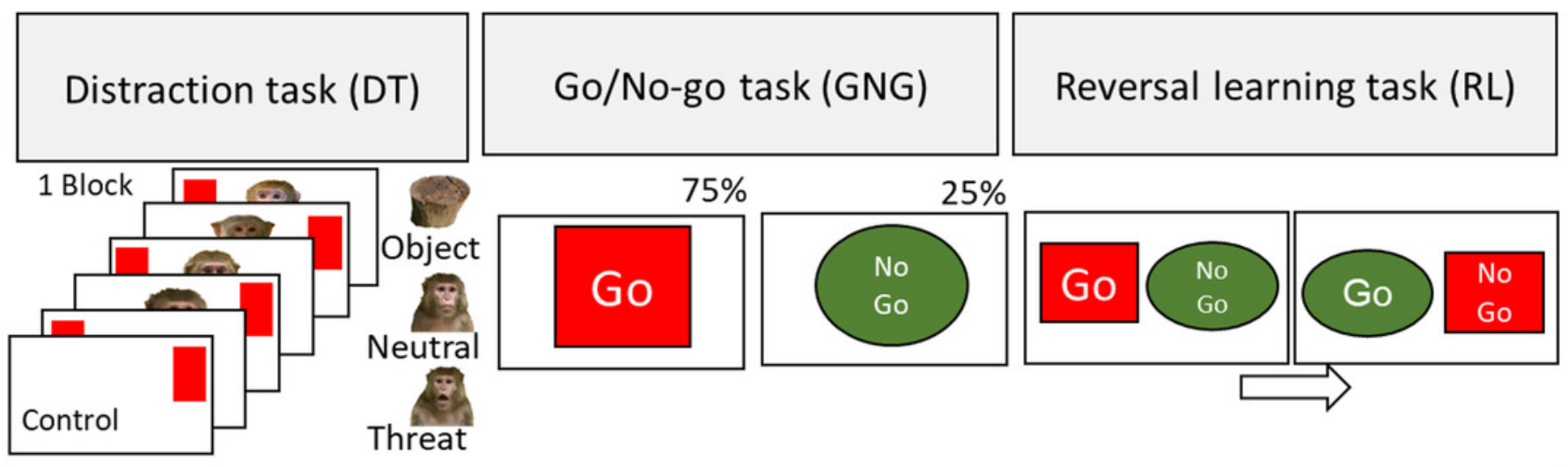

1. Content validity: was a prepotent response elicited and overridden?

2. Temporal repeatability: were rank of individual's performances within tasks repeatable between 2 time-points?

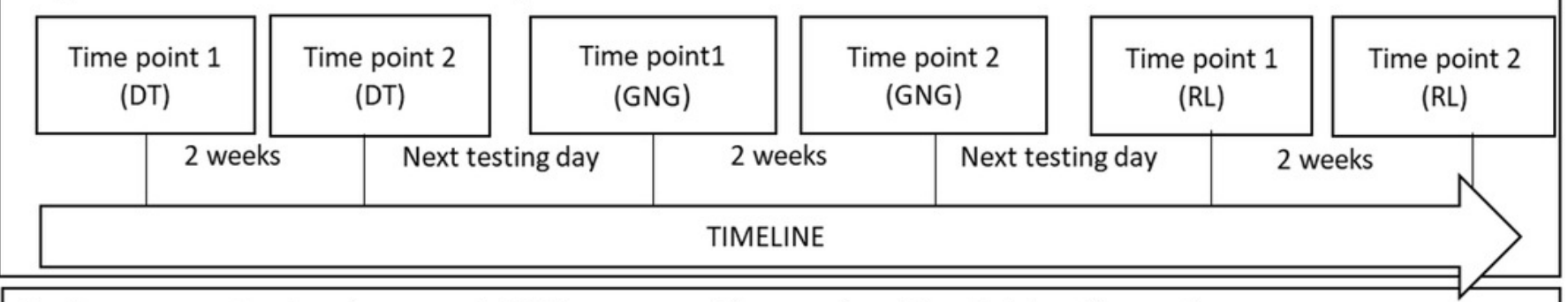

3. Cross-contextual repeatability: were the rank of individual's performances consistent between tasks? 


\section{Figure 2}

Content validity of the inhibitory control tasks

Distraction task: a. response latency the absence (With no picture) or in the presence of a picture (With picture); Go/No-go task: b. proportion of success or c. response latency in Go or No-go trials; Reversal learning task: d. proportion of success when first (Rule 1) or second rule learnt (Rule 2). ${ }^{* * *}$ indicates that $\mathrm{p}$-value $<0.001$

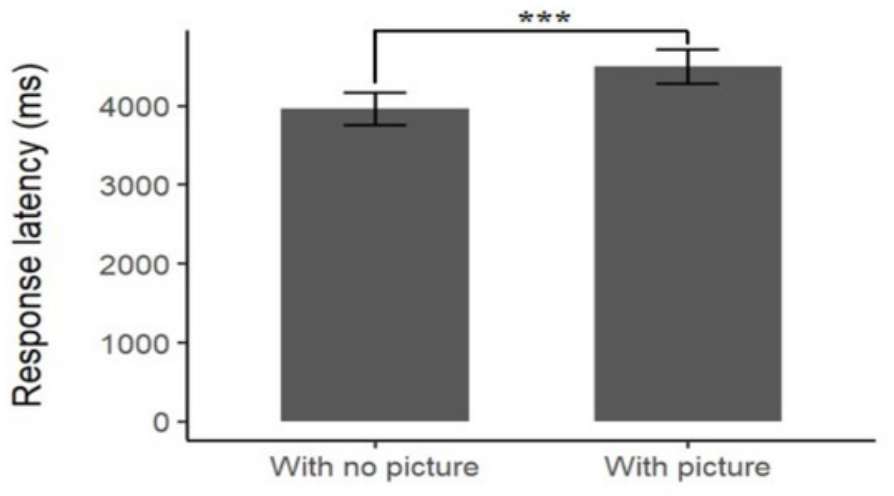

a. Type of trial of the Modified Stroop task

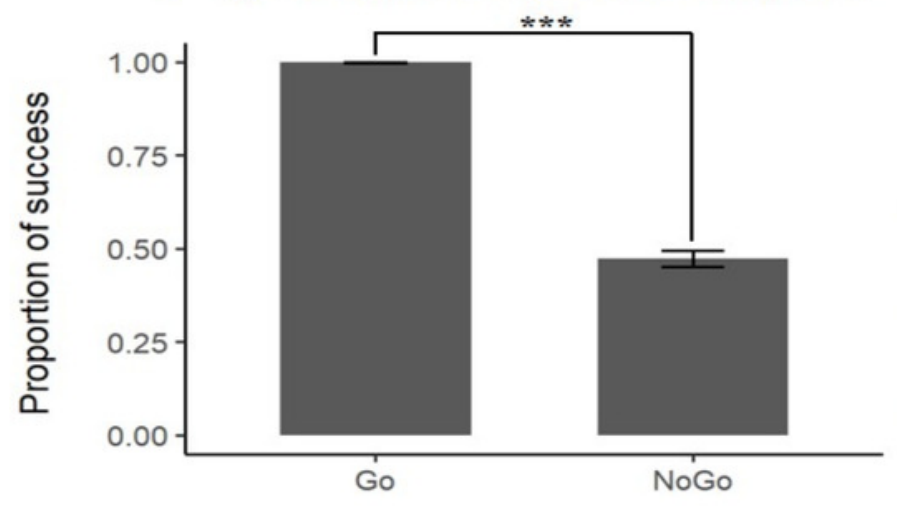

c. Type of trial of the Go/No-go

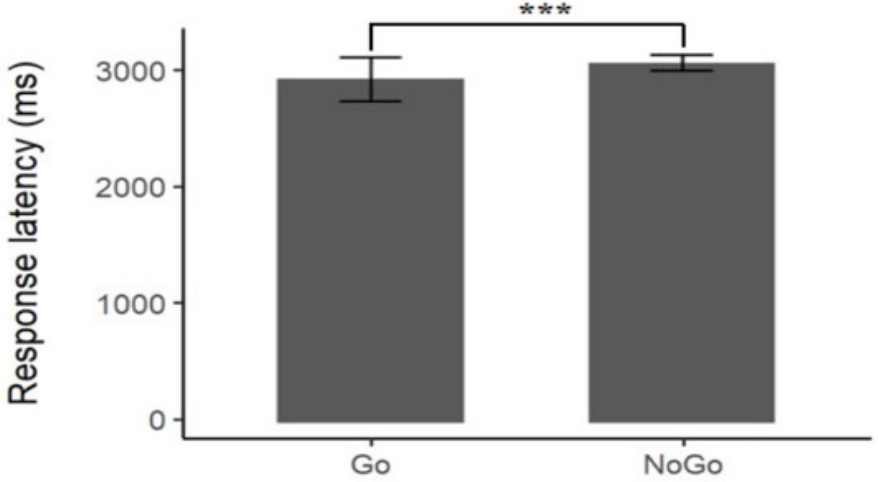

b. Type of trial of the Go/No-go

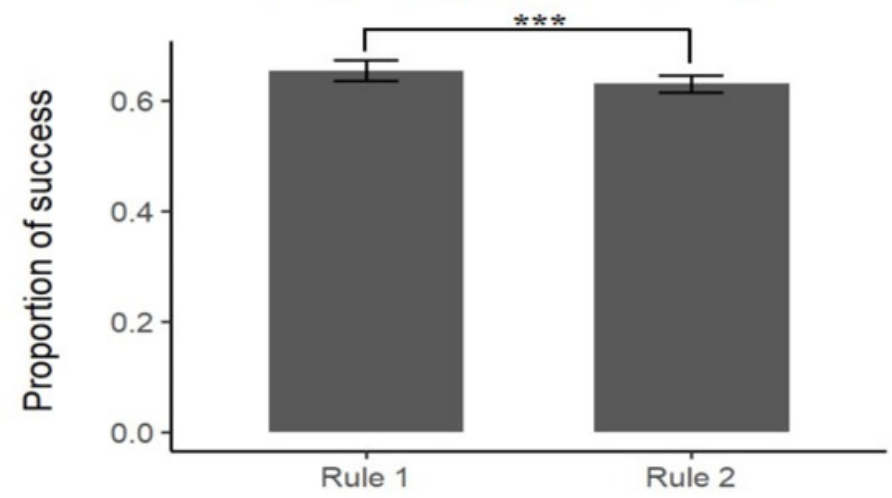

d. Type of Rule of the Reversal Learning 


\section{Figure 3}

Temporal repeatability $\mathrm{R}_{\text {adj }}$ (adjusted only for the Distraction control score) and $95 \%$ bootstrapped confidence intervals for inhibitory control scores.

$\mathrm{Y}$-axis presents the adjusted repeatability for each type of inhibitory control measurement: executive function (Executive function response latency), Distraction task (Distraction control score), Go/No-go (Action control score) and Reversal learning (Rule control score).

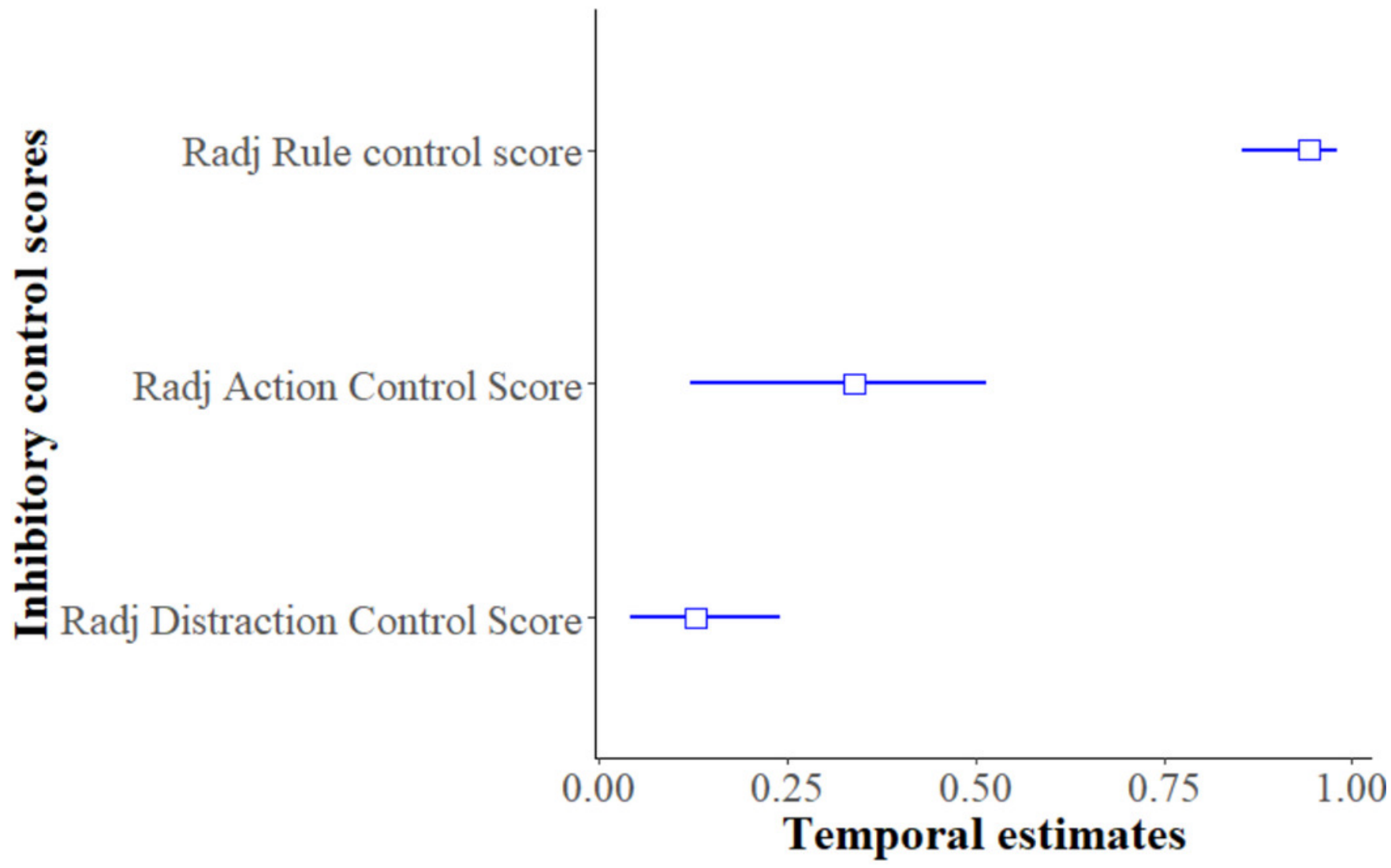




\section{Table $\mathbf{1}$ (on next page)}

Summary table presenting the main findings of the study. All tasks have demonstrated content validity, whereby a prepotent response was elicited and overridden. All individual's performances were repeatable over 2 time points. The individual's performance 


\begin{tabular}{|c|c|c|c|}
\hline & $\begin{array}{l}\text { Content validity: } \\
\text { - prepotent response } \\
\text { - overridden }\end{array}$ & $\begin{array}{l}\text { Repeatability of } \\
\text { performances over } 2 \\
\text { time points }\end{array}$ & $\begin{array}{l}\text { Contextual } \\
\text { repeatability }\end{array}$ \\
\hline Distraction task & $\begin{array}{l}\text { - Response latency } \\
\text { longer when pictures } \\
\text { presented } \\
\text { - But still high success }\end{array}$ & $\begin{array}{l}\text { Moderate }(R=0.282) \\
\text { Adjusted for sex, } \\
\text { session and time point } \\
\left(R_{\text {adj }}=0.128\right)\end{array}$ & $\begin{array}{l}\text { With the Go/No-go } \\
\text { task }\end{array}$ \\
\hline Go/No-go task & $\begin{array}{l}\text { - Success on No-go } \\
\text { trials lower than Go } \\
\text { trials } \\
\text { - Response latency } \\
\text { longer for No-go trials }\end{array}$ & $\begin{array}{l}\text { High }(R=0.338) \\
\text { Not adjusted }\end{array}$ & $\begin{array}{l}\text { With the Distraction } \\
\text { task }\end{array}$ \\
\hline $\begin{array}{l}\text { Reversal learning } \\
\text { task }\end{array}$ & $\begin{array}{l}\text { - Probability of success } \\
\text { lower for the reversed } \\
\text { than for the } \\
\text { acquisition rule } \\
\text { - But still high success }\end{array}$ & $\begin{array}{l}\text { High }(R=0.944) \\
\text { Not adjusted }\end{array}$ & With no other tasks \\
\hline
\end{tabular}

1 


\section{Table 2 (on next page)}

Contextual adjusted repeatability estimates of the scores of inhibitory control. Distraction control score (Distraction task), Action control score (Go/No-go task), Rule control score (Reversal Learning task).

The check mark Indicates that the individual's performances are significantly repeatable between tasks $* p<0.05, * * p<0.01,{ }^{* * *} p<0.0011$ 


\begin{tabular}{lccc}
$\begin{array}{l}\text { Contextual } \mathrm{R}_{\mathrm{adj}} \text { for } \\
\text { the scores }\end{array}$ & Distraction control & $\begin{array}{c}\text { Action } \\
\text { control }\end{array}$ & $\begin{array}{c}\text { Rule } \\
\text { control }\end{array}$ \\
\hline Distraction control & 1 & - & - \\
& $\checkmark \quad 0.170$ & 1 & - \\
Action control & $(\mathrm{p}<0.001)^{* * *}$ & & 1 \\
Rule control & 0.09 & 0.101 & \\
& $(\mathrm{p}=0.07)$ & $(\mathrm{p}=0.07)$ &
\end{tabular}

1 